\title{
LA RESPONSABILIDAD CIVIL DEL ASEGURADOR DE ASISTENCIA SANITARIA POR NEGLIGENCIAS MÉDICO- HOSPITALARIAS DE SU CUADRO ASISTENCIAL
}

\author{
THE CIVIL LIABILITY OF THE HEALTH CARE \\ INSURER FOR MEDICAL-HOSPITAL NEGLIGENCES \\ OF HIS MEDICAL CARE
}

\footnotetext{
FERNANDO CARBAJO CASCÓN*

Fecha de recepción: 29 de diciembre de 2021 Fecha de aceptación:10 de diciembre de 2021 Disponible en línea: 30 de diciembre de 2021

Para Citar este artículo/To cite this article

Carbajo Cascón, Fernando. La responsabilidad civil del asegurador de asistencia sanitaria por negligencias médico-hospitalarias de su cuadro asistencial, 55 Rev.Ibero-Latinoam. Seguros, 143-180 (2021). https://doi.org/10.11144/Javeriana.ris55.rcaa

doi:10.11144/Javeriana.ris55.rcaa
}

* Catedrático de Derecho Mercantil de la Universidad de Salamanca. Decano de la Facultad de Derecho. Magistrado de la Audiencia Provincial de Salamanca. Correo electrónico: nano@usal.es. ORCID ID: 00000002-9708-3791. 


\section{RESUMEN}

Los seguros de asistencia sanitaria predominan históricamente en la práctica aseguradora española de los seguros de salud. La expansión de este tipo de seguros entre el conjunto de la población ha dado lugar a una línea jurisprudencial consolidada - pero no por ello menos discutible- que, con la vista puesta en la mayor tutela de los asegurados como consumidores de servicios sanitarios, hace responsable directo al asegurador de los daños y perjuicios derivados de una asistencia sanitaria deficiente por parte de los médicos, sanitarios y hospitales incluidos en su cuadro asistencial.

Palabras Clave: Seguros de salud. Enfermedad y asistencia sanitaria. Responsabilidad civil médica. Responsabilidad del asegurador de asistencia sanitaria.

\section{ABSTRACT}

Health care insurance has historically predominated in the Spanish insurance practice of health insurance. The expansion of this type of insurance among the population as a whole, has given rise to a consolidated jurisprudential line-but not less debatable-that, with a view to the greater protection of the insured as consumers of health services, makes the insurer directly liable for damages arising from poor health care by the doctors, health workers and hospitals included in its care chart.

Keywords: Health insurance. Illness and healthcare. Medical liability. Liability of the health care insurer

SUMARIO:I.INTRODUCCIÓN.ELSEGURODEASISTENCIASANITARIA EN EL MARCO GENERAL DE LA LEY DE CONTRATO DE SEGURO. II. DELIMITACIÓN DEL SEGURO DE ASISTENCIA SANITARIA DENTRO DEL RAMO DE SEGUROS DE ENFERMEDAD. III. LA PRESTACIÓN DEL ASEGURADOR DE ASISTENCIA SANITARIA. IV. ALCANCE DE LA COBERTURA COMPROMETIDA POR EL ASEGURADOR: ¿GARANTIZA EL ASEGURADOR LA CORRECTA EJECUCIÓN DE LOS SERVICIOS SANITARIOS? ¿DEBE RESPONDER POR LAS NEGLIGENCIAS DE SU CUADRO MÉDICO Y HOSPITALARIO?: 1. Consideraciones previas. 2. Doctrina jurisprudencial sobre la responsabilidad del asegurador de asistencia sanitaria. V. CRÍTICA DE LA DOCTRINA JURISPRUDENCIAL Y PROPUESTA DE REVISIÓN. VI. CONSIDERACIONES FINALES. VII. BIBLIOGRAFÍA 


\section{INTRODUCCIÓN. EL SEGURO DE ASISTENCIA SANITARIA EN EL MARCO GENERAL DE LA LEY DE CONTRATO DE SEGURO}

Según el art. 1 de la Ley 50/1980, de 8 de octubre, de Contrato de Seguro (LCS), "(E)l contrato de seguro es aquel por el que el asegurador se obliga, mediante el cobro de una prima y para el caso de que se produzca el evento cuyo riesgo es objeto de cobertura a indemnizar, dentro de los límites pactados, el daño producido al asegurado o satisfacer un capital, una renta u otras prestaciones convenidas".

La Ley da una definición unitaria de contrato de seguro aplicable a las distintas modalidades de seguros, estén o no tipificadas en la misma (v.gr., seguros de natalidad, nupcialidad, decesos, asistencia turística u otros tipos de asistencia, etc.). Y delimita, en principio, los tipos de seguros por la naturaleza de la prestación asumida por el asegurador: indemnizatoria, satisfacción de un capital u otras prestaciones que se hubieran convenido; con lo cual reconoce un espacio de libertad a las partes (ex art. $1255 \mathrm{CC}$ ) para pactar en el contrato el objeto de la prestación del asegurador, y reconoce también la libertad de empresa del asegurador (ex art. $38 \mathrm{CE}$ ) para organizar y ofrecer coberturas de naturaleza diferente a las indemnizatorias y de sumas o rentas.

Sin embargo, después de establecer unas disposiciones comunes para todos los tipos de seguros (Título I), la misma LCS sistematiza luego las diferentes modalidades de seguros tipificadas en función del objeto del riesgo asegurado con cada seguro, estableciendo dos grandes grupos o subcategorías: seguros de daños, en los que el riesgo incide sobre bienes materiales o sobre el patrimonio (Título II); y seguros de personas, donde el riesgo recae directamente sobre el ser humano: sobre su existencia, integridad corporal o salud (Título III).

Esta distinción en dos grandes grupos de seguros ha servido de apoyo a la teoría dualista del seguro, que defiende la imposibilidad de aportar una definición y un tratamiento unitarios para todos los contratos de seguros, a la vista de las evidentes diferencias que existen entre los seguros de daños y los seguros de personas en relación con el objeto del riesgo asegurado y con la naturaleza de las prestaciones comprometidas por el asegurador en cada categoría de seguros ${ }^{1}$. La summa divisio entre seguros de daños y seguros de personas, en la que se justifica la teoría dualista, aparecía asociada tradicionalmente a la distinción entre seguros de indemnización efectiva, propios de los seguros de daños sobre bienes y sobre el patrimonio, y seguros de sumas o de capitalización, tomando como referencia al seguro de vida. Esta asociación o relación entre grupos de seguros en función del riesgo y la cobertura encuentra su explicación en un momento histórico (Siglo XIX) en que el único referente de los seguros de personas era el seguro de vida, principal exponente de los seguros de sumas o rentas

\footnotetext{
${ }^{1}$ La tesis dualista fue patrocinada en nuestro país principalmente por el maestro Joaquín GARRIGUES, Contrato de Seguro Terrestre, $1^{\mathrm{a}}$ ed., Madrid, 1973, pp. 36 y ss; $2^{\mathrm{a}}$ ed., Madrid, 1983, pp. 28 y ss. Vid. también Luis De Angulo RodríGuez, "Sobre la regulación de los seguros de personas", en AA.VV., Estudios de Derecho Mercantil en Homenaje al Profesor Justino F. Duque Domínguez, Vol. II, Universidad de Valladolid/Caja Duero, Valladolid, 1998, pp. 1157-1158.
} 
(seguros de previsión voluntaria, que buscan la obtención de una suma de dinero o una renta periódica para el caso de que se produzca el fallecimiento o la sobrevivencia a una determinada edad mediante la capitalización de las cantidades entregadas como prima), llegando a considerar que todo seguro de personas era un seguro de capitalización. Pero la posterior aparición y desarrollo, ya comenzado el Siglo XX, de los seguros de accidentes y enfermedad, rompió esa relación entre seguros de personas y seguros de capitalización ${ }^{2}$, ya que estas nuevas modalidades de seguros de personas incorporan tanto prestaciones a tanto alzado - de rentas o sumas- a modo de previsión caso de producirse el siniestro, como prestaciones indemnizatorias -exclusivas, hasta entonces, de los seguros de daños-en concepto de reembolso de gastos médicos y farmacéuticos ${ }^{3}$.

El difícil encaje de algunas modalidades de seguros de personas dentro de la categoría de seguros de sumas, impulsaron la teoría monista del contrato de seguro, que comprende por igual seguros de daños y seguros de personas en sus distintas modalidades. La teoría monista o unitaria del contrato de seguro propone una comprensión única y general para todos los contratos de seguro, independientemente de cuál sea el riesgo asegurado y cuál la naturaleza de la prestación asumida por el asegurador, basándose en la finalidad y en los elementos comunes a todos los seguros y reconduciendo en último término la función de previsión propia de los seguros de sumas a una función indemnizatoria lato sensu $u^{4}$. La definición unitaria del contrato de seguro (art. 1 LCS) y la existencia de disposiciones comunes a todos los contratos de seguros (Título I, arts. 1-24 LCS), construidas fundamentalmente en las características propias de los seguros de daños, son los elementos normativos sobre los que se sustenta la teoría monista, superando la artificial diferencia entre seguros de daños y seguros de personas en función del objeto del riesgo. La teoría monista se construye sobre la consideración unitaria del contrato de seguro bajo la perspectiva de la causa-función, como finalidad objetiva perseguida por las partes en el contrato de seguro, y que consistiría en la cobertura del riesgo ajeno por parte del asegurador, a cambio de una prima, para el caso de que aquél llegue a concretarse produciendo un daño, ofreciendo así una seguridad o garantía al asegurado. De esta forma, mediante la abstracción se logra aislar el contrato de seguro de los elementos particulares de cada tipo concreto de seguro para centrarse en los elementos comunes a todas las modalidades de seguros; en particular el riesgo, en tanto en cuanto, la prestación del asegurador depende, en cualquier clase de seguro, de que se produzca el evento cuyo riesgo es objeto de cobertura. En todo contrato de seguro, el tomador o contratante del seguro, a cambio de una prima, busca prevenirse, mediante la prestación ofrecida por el asegurador, frente a la posibilidad incierta (aleatoria) de que llegue a producirse

\footnotetext{
2 Vid. Luis Alberto Marco Arcalá, Seguros de personas. Aspectos generales, Thomson-Aranzadi, Navarra, 2006, pp. 31-32.

3 Vid. Giuseppe Fanelli, "La "summa divisio" delle assicurazioni private: riflessioni su di un vecchio problema”, en AA.VV., Saggi di Diritto delle Assicurazioni, Giuffrè, Milano, 1971, pp. 493 y ss.

4 Vid. Antigono Donati, Tratatto del diritto delle assicurazioni private, Milano, 1954, III, pp. 508 y ss. Esta tesis fue defendida en España por el maestro Rodrigo URÍA, "Orientaciones modernas sobre el contrato de seguro", Revista de Derecho Mercantil (RDM), no 84, 1962, pp. 263 y ss. Y ha sido continuada luego, tras la aprobación de la LCS 1980, por Fernando SÁNCHEZ CALERO, "Comentario al artículo 1", en Fernando SÁnchez Calero (Dir), Comentarios a la Ley de Contrato de Seguro, Thomson-Aranzadi, $4^{\mathrm{a}}$ ed., 2010, pp. 36-37.
} 
el evento dañoso (siniestro) que constituye la concreción del riesgo asegurado. Junto al riesgo se sitúa comúnmente, como elemento fundamental adicional, el interés asegurado, que hace referencia a la relación, susceptible de valoración económica, entre el asegurado y el objeto del riesgo asegurado.

El reconocimiento legal de la asistencia sanitaria como modalidad o ramo específico de seguro en España, a mediados del siglo XX por la LOSP 1954, y su consagración posterior como tipo contractual en la LCS 1980, introdujo un elemento importante de distorsión en la teoría general del contrato de seguro. Por una parte, con la tipificación legal del seguro de asistencia sanitaria se dio un paso hacia la ruptura de la relación establecida tradicionalmente entre los seguros de daños y las prestaciones pecuniarias indemnizatorias, de un lado, y los seguros de personas y prestaciones pecuniarias a tanto alzado o de sumas, de otro lado. Por otra parte, el seguro de asistencia sanitaria fue, en la LCS 1980, el único seguro de personas en el que no se contemplaba la prestación de sumas o prestación a tanto alzado. Y, finalmente, el seguro de asistencia sanitaria se muestra desde entonces como la punta de lanza de los seguros de prestación de servicios, entendidos hoy día por un sector cada vez más apreciable de la doctrina científica como tertium genus o tercera modalidad de prestaciones a las que puede comprometerse el asegurador; apareciendo luego sucesivamente los seguros de defensa jurídica, de decesos, de asistencia turística y de asistencia por dependencia, en lo que vendría a constituir una quiebra completa de la tradicional división por grandes bloques entre seguros de indemnización efectiva y seguros de sumas ${ }^{5}$.

La definición unitaria del seguro admitiendo diversas prestaciones o coberturas de las empresas aseguradoras (art. 1 LCS), es buena muestra del entorno liberalizador que caracteriza la legislación sobre seguros desde los años 80 del Siglo XX, consagrando la libertad de contratación y la libertad de empresa en el sector asegurador y abriendo las puertas a prestaciones diferentes a las pecuniarias -indemnizatorias y de sumas-, sean prestaciones indemnizatorias de reparación o reposición del objeto siniestrado (cfr., art. 18 II LCS), o sean prestaciones de hacer en forma de prestación o provisión de servicios (seguros asistenciales), que tanto desarrollo han tenido en las décadas posteriores a la aprobación de la LCS 1980.

Entiendo, por tanto, que actualmente existen argumentos suficientes para sostener con rigor que la falta de uniformidad conceptual y material entre los diferentes tipos de seguros hacen inútiles los esfuerzos por integrar las diferentes modalidades de seguro en una única categoría de contrato de seguro, así como los intentos por sistematizar los seguros privados en grandes bloques en función del objeto del riesgo asegurado, surgiendo con fuerza una concepción pluralista o atomizada de los contratos de seguro en la que, como evolución dialéctica a partir del concepto básico y unitario de seguro, adquiere un carácter prevalente o fundamental la determinación de la naturaleza y función de la prestación a la que se compromete el asegurador en cada tipo concreto de contrato de seguro ${ }^{6}$. A mi juicio, la atomización del panorama asegurador hace

\footnotetext{
5 Vid. Abel B. Veiga Copo. Tratado del Contrato de Seguro, T. I, $6^{\mathrm{a}}$ ed., Thomson Reuters Civitas, Madrid, 2019 , pp. 161 y ss.

${ }^{6}$ El principal referente de esta concepción es el trabajo de Gianguido ScALFI. "Dalla classificazione dualistica alla concezione pluralistica dei contratti di assicurazione: contratto o contratti di assicurazione?",
} 
que resulte más coherente con la realidad del sector, tanto en el plano contractual como en el de control y supervisión, distinguir los seguros privados adoptando como criterio determinante, pero no exclusivo, las prestaciones u obligaciones concretas asumidas por el asegurador en cada tipo o modalidad de seguro ${ }^{7}$; máxime cuando un mismo riesgo genérico (v.gr., la enfermedad) puede concretarse en riesgos específicos (pérdida de oportunidad por incapacidad temporal o permanente, pérdida patrimonial por gastos médico-farmacéuticos, o necesidad de asistencia sanitaria médicohospitalaria), y que, por tanto, la cobertura del riesgo puede llevarse a cabo a través de distintas modalidades de seguro.

El trabajo de distinción entre diferentes modalidades de seguros y el conocimiento preciso de la naturaleza y estructura íntima de cada tipo concreto (la estructuración concreta de cada seguro), tiene lugar no sobre la causa y el objeto del contrato apreciados en abstracto (donde los elementos riesgo e interés se toman con carácter general para los distintos seguros), ni tampoco exclusivamente sobre la prestación abstracta de garantía o de seguridad ofrecida por el asegurador, sino sobre la combinación analítica de la causa concreta y el objeto específico de cada tipo concreto de seguro. Considero que el conocimiento preciso de cada tipo determinado de seguro sólo puede extraerse mediante un examen combinado del riesgo específico asegurado (robo, incendio, muerte, lesiones, enfermedad) con la concreta prestación comprometida por el asegurador (indemnizatoria pecuniaria o de reparación; renta o capital; prestación de servicios; mixta de varias o todas las anteriores) para el caso de que llegue a producirse el riesgo asegurado ${ }^{8}$. Teniendo en cuenta también, a tales fines, los criterios de determinación de la prestación a percibir en caso de siniestro en cada clase de contrato de seguro (la determinación a priori mediante técnicas de capitalización en los seguros de sumas o rentas; la determinación a posteriori mediante la indemnización pecuniaria del daño producido o la reparación del objeto siniestrado en los seguros de daños; y...a mi entender, la determinación y provisión a priori del catálogo de servicios ofrecidos en los seguros asistenciales) ${ }^{9}$, que influyen en las medidas que debe adoptar cada entidad aseguradora para estar en condiciones de afrontar sus compromisos llegado el caso de producirse el evento riesgoso y, con ello, en las técnicas y previsiones de control y supervisión de tales medidas por parte de la Administración competente.

Materialmente puede decirse que no existe una dupla de riesgos posibles (cosas y personas), sino una multiplicidad de riesgos concretos (transporte, pérdida de mercancías, incendio, ilícito cometido contra un tercero, pérdida pecuniaria, muerte o supervivencia, enfermedad, natalidad, etc.). Como tampoco existe una tripla de prestaciones (indemnizatoria, de previsión y de asistencia), sino una multiplicidad de prestaciones específicas (indemnización pecuniaria, indemnización de reparación o reposición, sumas o rentas por días de baja laboral o por hospitalización, ahorro y

Assicurazione, 1995-3, pp. 143 y ss. Cfr., en la doctrina española, Pablo MarTínez-Gijón MaCHUCA. El seguro privado de asistencia sanitaria, Fundación Mapfre, Madrid, 2002, pp. 16 y ss. y 34 y ss.

7 Vid. Abel B. Veiga Copo, Tratado del Contrato de Seguro, 6 ed., cit., p. 171.

${ }^{8}$ SCALFI, Dalla classificazione dualistica alla concezione pluralistica dei contratti di assicurazione: contratto o contratti di assicurazione?, cit., pp. 145-148.

9 Cfr., Marco Arcalá, Seguros de personas. Aspectos generales, cit., p. 33. 
capitalización, asistencia sanitaria, asistencia en viaje, asistencia en decesos, asistencia por dependencia, etc.), que además pueden combinarse entre sí de diferentes formas (rentas y reembolso de gastos; rentas y asistencia; asistencia y reembolso, etc.). En suma, la diversidad en la tipología de riesgos se traduce en la misma diversidad tipológica de coberturas de seguridad por parte del asegurador, y ambas -en conexión necesaria- determinan la naturaleza y la estructura concreta de cada tipo o modalidad de seguro.

Los denominados seguros asistenciales o seguros de prestación de servicios y, en particular, el seguro de asistencia sanitaria o de prestación de servicios médicos, quirúrgicos y hospitalarios, son probablemente las modalidades de seguros que mejor definen la ruptura con los conceptos, categorías y clasificaciones tradicionales apuntada anteriormente, así como la necesidad de un examen de su estructura y función concretas mediante el recurso al método tipológico. De modo tal que el seguro de asistencia sanitaria, por su reconocida tradición y amplia implantación en España, puede reconocerse como paradigma de la categoría concreta-general de seguros asistenciales o de prestación de servicios, dentro del concepto abstracto-general del contrato de seguro.

El art. 105 LCS 1980 se ocupa de los seguros de enfermedad y asistencia sanitaria en los siguientes términos: "Cuando el riesgo asegurado sea la enfermedad, el asegurador podrá obligarse, dentro de los límites de la póliza, en caso de siniestro, al pago de ciertas sumas y de los gastos de asistencia médica y farmacéutica. Si el asegurador asume directamente la prestación de los servicios médicos y quirúrgicos, la realización de tales servicios se efectuará dentro de los límites y condiciones que las disposiciones reglamentarias determinan".

El referido art. 105 LCS parece tipificar legalmente el seguro de asistencia sanitaria como tipo o modalidad específica de seguro junto al seguro de enfermedad, incluyéndolo, como hemos visto -por razón del objeto del riesgo asegurado-, en la categoría de los seguros de personas. El legislador de 1980 prácticamente se limita a definir, o mejor, a describir el seguro de asistencia sanitaria, pero no establece un régimen o estatuto jurídico concreto, sino que se limita a declarar aplicables al mismo las disposiciones generales sobre seguros de personas (arts. 80-82 LCS) y las normas previstas para los seguros de accidentes en cuanto sean compatibles con el mismo (art. 106 LCS), remitiéndose, para lo demás, a un desarrollo reglamentario que discipline la realización de los servicios sanitarios dentro de unos límites y condiciones (Art. 105 in fine LCS), que nunca ha llegado a producirse.

La falta de un régimen jurídico adecuado a las particulares y dificultades propias del seguro de asistencia sanitaria, obliga al intérprete a realizar una reconstrucción del concepto y estructura del tipo concreto a partir de sus antecedentes históricos, de la intención perseguida por el legislador con su tipificación y de su desarrollo empírico en contraste con otros tipos de seguros que comparten algunos elementos o notas comunes, partiendo del reconocimiento de las prestaciones de servicios o asistenciales tanto -de forma tácita- en el concepto general de contrato de seguro (art. 1 LCS) como en la normativa administrativa sobre clasificación de ramos de riesgos asegurables (Ramo 2: enfermedad, asistencia sanitaria y asistencia a la dependencia; y Ramo18: asistencia 
turística y otras prestaciones no definidas de asistencia en caso de necesidad, ambos del art. 2 del TRLOSSP). Esta construcción del régimen jurídico propio del seguro de asistencia sanitaria resulta fundamental para resolver problemas de índole práctica, como el que nos ocupa en este trabajo: la posible responsabilidad del asegurador de asistencia sanitaria por los daños derivados de negligencias médico-hospitalarias cometidas por los centros y profesionales incluidos en su cuadro médico-asistencial.

\section{DELIMITACIÓN DEL SEGURO DE ASISTENCIA SANITARIA DENTRO DEL RAMO DE SEGUROS DE ENFERMEDAD}

De acuerdo con la sistemática seguida por la LCS 1980, el seguro de enfermedad y el seguro de asistencia sanitaria se agrupan en el art. 105 LCD dentro de la categoría de los seguros de personas (Título III LCS) atendiendo a la naturaleza del riesgo asegurado: la enfermedad. Lo que hace el art. 105 LCS es identificar claramente dos tipos de seguros distintos que recaen sobre un mismo riesgo asegurado ${ }^{10}$. Efectivamente, ambas modalidades de seguros de salud persiguen una misma finalidad: ofrecer cobertura o garantía al asegurado frente al riesgo de que tenga que afrontar, por sus propios medios, las consecuencias de la enfermedad o lesión ${ }^{11}$. Pero los tipos contractuales de seguros se identifican no sólo por el riesgo asegurado, sino también por la prestación o cobertura a que se obliga el asegurador; aspecto éste que resulta ser fundamental en la caracterización del seguro de asistencia sanitaria frente al seguro de enfermedad. Así, en el seguro de enfermedad propiamente dicho, el asegurador se obliga al pago de ciertas sumas y reembolso de gastos de asistencia médica y farmacéutica, mientras que en el seguro de asistencia sanitaria -según el tenor legal- el asegurador asume directamente la prestación de servicios médicos y quirúrgicos, en línea, por tanto, con el art. 1 LCS que admite prestaciones o coberturas indemnizatorias de daños, de sumas o satisfacción de un capital o renta "u otras prestaciones convenidas", abriendo el camino a los modernos seguros asistenciales o de prestación de servicios ${ }^{12}$.

En la normativa técnica, la vigente Ley 20/2015, de 14 de julio, de ordenación, supervisión y solvencia de las entidades aseguradoras (LOSSEAR) establece en su Anexo la clasificación de ramos de seguros (actividades de las compañías aseguradoras),

\footnotetext{
${ }_{10}$ Realmente lo que se pretendía era tipificar un seguro de enfermedad de forma amplia, a modo de tipo general en función del riesgo, distinguiendo luego tipos concretos en función de las prestaciones comprometidas por el asegurador, entremezclando así riesgo y naturaleza de la prestación como criterios clasificatorios. El caso, sea como fuere, es que influyó notablemente en la mente del legislador el peso específico adquirido por el seguro de asistencia sanitaria en la práctica aseguradora de nuestro país, abocando a su presentación, siquiera indirecta, como un tipo de seguro distinto (y probablemente autónomo) del seguro de enfermedad en sentido estricto, tal y como éste era conocido tradicionalmente por el sector asegurador.

11 Vid. Miquel Martín Casals, Jordi Ribot Igualada y Josep Solé Feliú. La responsabilidad de las entidades de seguros de salud en las reclamaciones judiciales por errores o negligencias médicas, Cuadernos de SEAIDA, noviembre de 2006, p. 12.

12 Vid. al respecto Gabriela GonzÁlez BuEno. "Hacia nuevas formas de vender seguridad a través de prestaciones de asistencia”, Revista Española del Seguro (RES), n³ 39, 1984, pp. 442 y ss.
} 
incluyendo en el Ramo 2 del apartado A), relativo a los Seguros distintos al seguro de vida y riesgos accesorios, a los seguros de enfermedad, comprendida la asistencia sanitaria y la dependencia, indicando que las prestaciones en este ramo pueden ser " $a$ tanto alzado, de reparación, bien mediante el reembolso de los gastos ocasionados, bien mediante la garantía de la prestación del servicio, y mixta de ambos"13. Esta agrupación sistemática del seguro de asistencia sanitaria -introducida por la LOSSP 1995 y continuado en el TRLOSSP 2004 y en la vigente LOSSEAR 2015-, eliminándolo como clase o ramo propio para incluirlo en el ramo de enfermedad, se explica por la necesidad de adaptar la normativa española sobre clasificación de ramos de seguros a la normativa comunitaria sobre seguros distintos al seguro de vida, que no contempla entre los ramos de aseguramiento el seguro de asistencia sanitaria por no estar contemplado de forma autónoma en el resto de países europeos ${ }^{14}$. Entiendo, sin embargo, partiendo de las especificidades del seguro de asistencia sanitaria en nuestro ordenamiento y del reconocimiento autónomo del mismo en el art. 105 LCS, que el legislador español no tendría que verse obligado a modificar la clasificación de ramos de seguros introducida por LOSP 1984 y la Orden del Ministerio de Economía y Hacienda de 7 de septiembre de 1987, en las que la asistencia sanitaria aparecía como un ramo propio de prestación de servicios. En primer lugar, porque, más allá de compartir el riesgo general asegurado, la asistencia sanitaria muestra notables especificidades respecto del seguro tradicional de enfermedad (concebido, este sí, como prestaciones a tanto alzado o de sumas e indemnizatorias o de reembolso). Y en segundo lugar, porque entiendo que la normativa de la UE, a pesar de no contemplar (por las razones antes apuntadas) el seguro de asistencia sanitaria, podría aún dejar margen para contemplar el ramo de asistencia sanitaria indirectamente ${ }^{15}$.

La inclusión del seguro de asistencia sanitaria en el ramo de enfermedad, donde sólo se contemplan prestaciones a tanto alzado, de reparación y mixta de ambos, ha producido un desajuste con la caracterización tradicional del mismo -influida claramente por sus antecedentes históricos- como seguro de prestación de servicios, aunque la indicación de que la reparación puede consistir en la garantía de prestación del servicio introducida con la LOSSEAR 2015 no deja de ser un homenaje a la realidad creciente de los seguros de servicios. Salvo que se califique abiertamente el seguro de asistencia sanitaria como un seguro indemnizatorio de las consecuencias económicas derivadas de la enfermedad, puede encontrarse una correspondencia lógica entre la prestación

\footnotetext{
13 Angulo Rodríguez. Sobre la regulación de los seguros de personas, cit., p. 1173, entiende que el TRLOSSP ha provocado una transformación en la situación del mercado al integrar el seguro de asistencia sanitaria en el mismo ramo que el de enfermedad, que venían siendo dos ramos diferentes.

14 Aunque en la praxis del sector salud o enfermedad de otros países de nuestro entorno sí que se ofrecen servicios de asistencia sanitaria recurriendo a la libertad de contratación (como se ofrecen también en el marco de seguros de asistencia turística y en algunas pólizas de accidentes), si bien su implantación no alcanza las cifras del mercado español, quedando muy por debajo de los tradicionales seguros de enfermedad en forma de reembolso de gastos sanitarios.

15 El art. 6.1 a) de la Directiva 2009/138/CE, Solvencia II, indica que dicha Directiva no se aplicará a la actividad de asistencia cuando la asistencia se preste con ocasión de un accidente o una avería que afecten a un vehículo de carretera, cuando sobrevengan en el territorio del Estado miembro del prestador de la garantía; con lo cual podría estar dejando margen a la existencia (y aplicación de la Directiva) de otros tipos o modalidades de coberturas asistenciales distintos de la asistencia turística, que podrían ser autorizados por las autoridades de los Estados miembros.
} 
de asistencia sanitaria y las prestaciones o coberturas indemnizatorias (pecuniaria o in natura) propias del seguro de enfermedad previstas en la legislación comunitaria y nacional de carácter técnico-asegurador ${ }^{16}$.

En cualquier caso, los desajustes normativos de nuestro ordenamiento de seguros no han restado autonomía al seguro de asistencia sanitaria ni en el campo de la práctica aseguradora española ni el terreno puramente conceptual. Tras la inserción del seguro de asistencia sanitaria en el ramo de enfermedad llevada a cabo por la LOSSP 1995 y ratificada en el TRLOSSP 2004 y en la LOSSEAR 2015, pudiera parecer que el seguro de asistencia sanitaria ha pasado de ser un seguro totalmente diferenciado del seguro de enfermedad a considerarse una submodalidad o subespecie del mismo (lo mismo que sucedería ahora con el seguro de dependencia) ${ }^{17}$. Sin embargo, entiendo que la integración del seguro de asistencia en el ramo de enfermedad dentro de la normativa de control y supervisión de los seguros privados tiene un alcance puramente formal, forzado (artificialmente) por la clasificación de ramos técnicos establecida en las Directivas no vida sobre la base del riesgo asegurado, pues parece claro que desde el punto de vista del contrato de seguro y, en concreto, de la prestación comprometida por el asegurador, así como desde la perspectiva misma del control y supervisión de la actividad aseguradora, el seguro de asistencia sanitaria constituye un tipo de seguro autónomo o de clase propia, específico e independiente respecto al seguro de enfermedad tradicional ${ }^{18}$.

Puede decirse, en suma, que en la legislación española el ramo de enfermedad se presenta como una categoría amplia de seguros, caracterizada por el riesgo de referencia, que es la enfermedad (entendida en sentido amplio) o -como defiende buena parte de la doctrina- las consecuencias patrimoniales de la enfermedad. Categoría dentro de la cual se desarrollan diferentes modelos o tipos específicos de seguros que pueden ofrecerse de manera independiente o combinada conformando una subcategoría alegal de seguros médicos o seguros de salud ${ }^{19}$. Así, por un lado las entidades aseguradoras que operan en el ramo técnico de enfermedad, ofrecen los tradicionales seguros de enfermedad en forma de seguros de sumas, rentas o capitales. Por otro lado ofrecen básicamente tres tipos de seguros de salud que cubren riesgos de enfermedad y también riesgos de accidentes, incluyendo distintos tipos de coberturas para el caso

\footnotetext{
16 En este sentido, Sánchez Calero, F. “Comentario al artículo 105 LCS”, 4a ed. 2010, pp. 2694-2695.

17 Vid. Guerrero de Castro. "El seguro de asistencia sanitaria. Sus problemas principales", cit., pp. 212 y ss. SÁnchez CALero. "Comentario al artículo 105 LCS”, cit., p. 2152. También, Ricardo De ÁngEL YAGÜEZ. "¿Responde el asegurador de asistencia sanitaria por la culpa de los médicos incluidos en sus listas?”, en Juan Antonio Moreno Martínez (Coord.). La Responsabilidad Civil y su problemática actual, Dykinson, Madrid, 2008, pp. 140 y ss.

18 Vid., Francisco Javier TiRAdo SuÁREZ. “¿El seguro de asistencia sanitaria y el seguro de enfermedad son el mismo ramo o son ramos diferentes?", Actualidad Aseguradora, septiembre 1992, pp. 28 y ss.; Idem, “Asistencia sanitaria, un ramo con fuerza propia”, Actualidad Aseguradora, marzo 1994, pp. 25 y ss; Vid. también, Pablo Martínez-Gijón Machuca. El seguro privado de asistencia sanitaria, cit., pp. 41-46. Fernando CARBAJO CASCón. La responsabilidad civil del asegurador de asistencia sanitaria, Fundación Mapfre, Instituto de Ciencias del Seguro, Cuadernos de la Colección, Madrid, 2012, pp. 56 y ss.

19 Vid. Martínez-Gijón Machuca. El seguro privado de asistencia sanitaria, cit., pp. 4 y ss. También, Mercedes VÁQUEZ de PADURA. "La responsabilidad ante el paciente de las entidades de seguro de asistencia sanitaria”, RES 2006, n 128, pp. 847-848.
} 
de que se produzca el evento dañoso (enfermedades, lesiones o accidentes). De una parte están los llamados seguros de reembolso de gastos médicos y farmacéuticos (o seguros médicos de reembolso, como los denominan algunas compañías), en los que la entidad aseguradora se compromete a reembolsar al asegurado los gastos -acreditados con facturas- abonados previamente por él en concepto de asistencia sanitaria (médico-quirúrgica-hospitalaria) y de adquisición de fármacos, hasta un capital máximo anual (suma asegurada) y, en su caso, deduciendo las franquicias que se pudieran haber previsto en la póliza para determinadas actuaciones u operaciones (v.gr., coberturas dentales amplias o la crío-preservación de las células madre del cordón umbilical). Aunque frecuentemente estas pólizas se presentan como seguros de reembolso de gastos de asistencia sanitaria, realmente no estamos ante un seguro de asistencia sanitaria como tal, sino ante un seguro de enfermedad de cobertura indemnizatoria ${ }^{20}$. De otra parte, los seguros de asistencia sanitaria propiamente dichos (o seguros médicos de cuadro médico en la terminología comercial del sector), en los que, a cambio de una prima, el asegurador asume la cobertura del riesgo que supone el hecho eventual de que el asegurado que sufra alguna enfermedad, lesión o accidente delimitados en la póliza deba ser atendido por personal y centros sanitarios incluidos en un cuadro o guía médica organizado y gestionado por el asegurador. Y finalmente están los seguros mixtos o combinados de asistencia sanitaria y enfermedad en su modalidad de reembolso de gastos médicos y farmacéuticos (aunque habitualmente se presentan como seguros de asistencia sanitaria con reembolso de gastos médicos), en los que el asegurador se compromete a poner a disposición del asegurado los servicios sanitarios que necesite para el tratamiento de su enfermedad, lesión o accidente, dentro del cuadro médico organizado al efecto, y, adicionalmente, a reembolsar ciertos gastos médicos y farmacéuticos originados al asegurado que hubiera recibido tratamiento sanitario fuera del cuadro médico predispuesto por el asegurador (atención de urgencias, servicios dentales, adquisición de prótesis... $)^{21}$ o que correspondan a la adquisición de ciertos materiales que no estuvieran incluidos en la prestación sanitaria propiamente dicha (gastos de prótesis, lentes, audífonos, marcapasos, etc.).

\section{LA PRESTACIÓN DEL ASEGURADOR DE ASISTENCIA SANITARIA}

Desde una perspectiva abstracta o general de la causa-función del contrato de seguro, la causa (el objetivo o finalidad objetiva perseguida por los contratantes) del contrato no reside en el riesgo asegurado, sino, realmente, en la cobertura del riesgo ofrecida por el asegurador a cambio de una prima; en la garantía o seguridad que el asegurador ofrece al asegurado a cambio de la prima. En concreto, la causa del contrato consistiría en el cambio entre la prima y la prestación de seguridad. El riesgo no es la causa

\footnotetext{
${ }^{20}$ Cfr., Martínez-GiJón Machuca. El seguro privado de asistencia sanitaria, cit., p. 4.

${ }^{21}$ En ocasiones se ofrecen seguros de reembolso de gastos médicos que pueden parecer mixtos (de reembolso y de asistencia sanitaria), por cuanto el asegurador ofrece una primera opción de libre elección del médico y hospital para recuperar luego los gastos ocasionados según los límites y porcentajes establecidos en la póliza, y una segunda opción de servicios médicos recomendados en los que el asegurado no tendrá que realizar desembolso alguno, siendo suficiente que se identifique como asegurado con su tarjeta.
} 
del contrato, sino que actúa más bien como elemento determinante del contrato, como presupuesto de la causa del contrato, pues la auténtica función de éste es la de ofrecer garantía o seguridad al asegurado frente a ese riesgo. Tampoco creo que pueda centrarse el objeto del contrato en el interés del tomador en el objeto asegurado (cosa, patrimonio o persona) expuesto al riesgo. Entiendo que el objeto del contrato de seguro, apreciado en abstracto, lo constituye la prestación de seguridad comprometida por el asegurador, ya que constituye la prestación principal o característica sobre la que descansa toda la estructura del contrato de seguro. El asegurador ofrece cobertura de un riesgo mediante una prestación de seguridad o garantía y el asegurado contrata el seguro porque tiene interés en obtener esa seguridad sobre el objeto del riesgo para el caso de que éste llegue a concretarse ${ }^{22}$.

El asegurador no se limita únicamente a soportar o asumir el riesgo del asegurado para el caso - eventual- de que tenga lugar el siniestro. Antes bien, desde el mismo momento de la celebración del contrato, el asegurador viene obligado a adoptar una serie de medidas para satisfacer el interés que tiene el asegurado sobre el objeto (cosa o persona) del riesgo por si éste llegare a producirse ${ }^{23}$. Esto implica que el asegurador viene obligado ex contractus a establecer las condiciones necesarias -constitución de reservas, índices de solvencia, organización de medios necesarios para proporcionar la cobertura, etc.- para hacer frente a las consecuencias del siniestro por si éste finalmente tuviera lugar, es decir, a adoptar medidas técnicas (patrimoniales, financieras, organizativas) para neutralizar el riesgo si llegara a concretarse. Y, de producirse esta situación, la cobertura del riesgo se determina mediante la prestación de la indemnización pactada (dineraria o no dineraria, ex art. 18 II LCS), la entrega de las sumas o rentas convenidas o la prestación de los servicios acordados.

Entonces, la obligación del asegurador consiste en ofrecer al asegurado una prestación de seguridad ante la amenaza que supone el riesgo asegurado, la cual surge inmediatamente con la perfección del contrato ${ }^{24}$. Esta prestación de seguridad, que se concibe en abstracto, tiene carácter inmediato o primario, y debe concretarse mediante una serie de actividades instrumentales o prestaciones secundarias: $a$ ) Una prestación intermedia o de previsión que consiste en la adopción de las medidas idóneas para organizar y garantizar la cobertura comprometida, que deberán implementarse en todo caso, llegue a producirse o no el siniestro, ofreciendo así al asegurado la seguridad de que su interés (el interés en recibir la prestación comprometida por el asegurador) está cubierto de antemano para el caso de que llegara a producirse el evento cuyo riesgo se asegura ${ }^{25} ; b$ )

\footnotetext{
22 Carbajo Cascón. La responsabilidad civil del asegurador de asistencia sanitaria, cit., pp. 70 y ss.

23 Cfr., Gianguido SCAlfi. I contratti di assicurazione. Asicurazione dei danni, Torino 1991, pp. 35 y ss.

24 SCALFI. L'Assicurazione tra rischio e finanza, cit., pp. 14-18.

25 Esta prestación de seguridad se refuerza con la intervención pública, mediante la normativa de control y supervisión de las entidades aseguradoras (TRLOSSP 2004), que exige a las empresas de seguros mantener unos índices determinados de solvencia patrimonial y financiera así como acreditar la organización de los medios necesarios para hacer frente a sus obligaciones de cobertura de riesgos. La intervención pública, armonizada a nivel comunitario (Directiva 2009/138/CE, Solvencia II), se justifica por el interés general que existe en el funcionamiento eficiente del mercado del riesgo, al estar ampliamente consolidado entre la sociedad, de manera que la seguridad ofrecida a través de los contratos de seguro sea real y efectiva para el conjunto de los asegurados, aunque individualmente no llegue a concretarse el riesgo ni, por tanto, a necesitar la cobertura concreta de esa seguridad.
} 
una prestación final, de carácter eventual, que sólo tendrá que llevarse a cabo si tiene lugar el evento o siniestro, y que consistirá - dependiendo del tipo concreto de seguroen la prestación material o efectiva de una indemnización (pecuniaria, de reparación o de reposición), en la entrega de un capital en forma de pago único o de renta periódica, o en la prestación de los servicios garantizados en la póliza ${ }^{26}$.

Frente a la abstracción que caracteriza a la prestación de seguridad o garantía común a todo contrato de seguro, el examen tipológico de una modalidad específica de seguro requiere tomar como referencia fundamental la prestación concreta, instrumental o de segundo grado; esto es, la prestación final, de carácter incierto, eventual o circunstancial a la que se compromete el asegurador en ese tipo determinado de seguro para el caso de que llegue a producirse el evento cuyo riesgo es objeto de cobertura, la cual hay que relacionar directamente con el riesgo y -en su caso-el interés propios de ese contrato de seguro. Y es que, si el evento finalmente se verifica, el asegurador deberá prestar la cobertura en forma diversa, en relación con la naturaleza del riesgo asegurado $^{27}$. Es, entonces, la prestación específica la que acaba por caracterizar el tipo concreto de contrato de seguro en análisis en cada caso, delineando a su vez el riesgo y el interés característicos de esa modalidad de seguro; y también la que predetermina a su vez la prestación u obligación intermedia -consecuencia directa de la prestación genérica o abstracta de seguridad que nace con todo contrato de seguro- consistente en la adopción de las medidas técnicas necesarias para organizar y garantizar la prestación de la cobertura específica comprometida en el contrato para el caso de que llegare a concretarse el riesgo asegurado.

Generalmente se entiende que el riesgo asegurado en el seguro de asistencia sanitaria es -como en todas las modalidades de seguro incluidas en el ramo 2 de la clasificación de ramos- la enfermedad del asegurado, que puede ser el mismo tomador del seguro o un tercero. La doctrina define la enfermedad como un estado anormal del cuerpo o del espíritu, según dictamen médico ${ }^{28}$; o como un quebranto físico o anímico que opera en manera diferente que en el accidente, ya que en éste se pasa de un estado de normalidad a otro de anormalidad de forma violenta o súbita, mientras que en la enfermedad ese decurso es gradual ${ }^{29}$. No obstante, en las pólizas de asistencia sanitaria suele contemplarse la enfermedad en sentido amplio, en el sentido propio del término recogido en el Diccionario de la Real Academia, esto es, como "alteración más o menos grave de la salud", independientemente de cuál sea la causa generadora de esa alteración de la salud. De hecho es habitual en estas pólizas que en la descripción del riesgo enfermedad se incluyan también -según los casos- lesiones producidas de manera fortuita o a raíz de un accidente, aunque sin incluir la invalidez temporal o

\footnotetext{
26 Vid. SÁnchez CAlero. Comentario al artículo 1 LCS, cit., $4^{\mathrm{a}}$ ed., pp. 53-54. Para una construcción más detallada de la estructura del contrato de seguro, vid. DAmiAnI. Contratto di assicurazione e prestazione di sicurezza, cit., pp. 121 y ss.

27 Scalfi, Dalla classificazione dualistica alla concezione pluralistica dei contratti di assicurazione..., cit., p. 147.

28 GARrigues, Contrato de seguro terrestre, cit., p. 545.

29 Mercedes Vergez, "Los seguros de accidentes y de enfermedad y asistencia sanitaria en la Ley de Contrato de Seguro (arts. 100 a 106)", en Evelio Verdera I Tuells (Coord.), Comentarios a la Ley de Contrato de Seguro, Vol. I, Madrid, 1982, p. 1069.
} 
permanente o la muerte, por ser éstos riesgos específicos de los seguros de accidentes (cfr., art. $100 \mathrm{LCS})^{30}$.

Así pues, la enfermedad es el riesgo genérico del seguro de asistencia sanitaria compartido con los seguros de enfermedad en sentido estricto (cfr., art. 105 LCS) y ahora también con los seguros de dependencia (cfr., ramo 2 en la clasificación de riesgos asegurados en el Anexo de la LOSSEAR 2015). Desde algún sector doctrinal se defiende que, a pesar de las diferentes prestaciones comprometidas por el asegurador en las distintas modalidades de seguros de salud, todas los contratos de seguros incluidos en el ramo de enfermedad persiguen una finalidad idéntica: ofrecer cobertura al asegurado frente al riesgo de tener que afrontar, por sus propios medios económicos, las consecuencias de la lesión o la enfermedad ${ }^{31}$. De esta manera nuevamente se pone el acento en la abstracción, aunque con un importante matiz: el riesgo en las distintas modalidades de seguros del ramo de enfermedad no sería la enfermedad propiamente dicha, sino las consecuencias económicas de la enfermedad para el patrimonio del asegurado. Sin embargo, entiendo que para analizar detalladamente la naturaleza y régimen jurídico de un tipo concreto de seguro -como es, en nuestro caso, el seguro de asistencia sanitaria-, es imprescindible centrar la atención en el riesgo concreto que actúa como presupuesto específico de la causa-función del contrato de seguro donde el riesgo genérico o riesgo-presupuesto es la enfermedad ${ }^{32}$.

Según el art. 105 LCS y tal y como se desprende de la práctica contractual del sector (condiciones generales) en el seguro de asistencia sanitaria el asegurador se compromete a prestar servicios médicos, quirúrgicos y hospitalarios. No a entregar una determinada suma de dinero, ni tampoco -al menos como obligación principal o fundamental- a reembolsar gastos médicos y farmacéuticos abonados previamente por el asegurado, como sucede en el seguro de enfermedad en sentido estricto. Cuestión distinta es que se pueda concertar un seguro mixto de asistencia sanitaria y reembolso de gastos para determinadas situaciones. La prestación concreta del asegurador en los seguros de enfermedad stricto sensu es siempre de carácter pecuniario, sea en forma de sumas o sea en forma de indemnización en concepto de reembolso de gastos médicos y farmacéuticos. Por el contrario, en el seguro de asistencia sanitaria la prestación concreta del asegurador, y la única a la que se compromete (sin perjuicio de las pólizas mixtas ya mencionadas) consistiría -según el tenor legal- en la asunción y prestación de atenciones sanitarias por el asegurador ${ }^{33}$.

Pues bien, como decimos, la prestación específica o particular a que se compromete el asegurador acaba por caracterizar el tipo contractual y por determinar su estructura contractual, incluyendo el riesgo (como presupuesto causal) y el interés concretos de

\footnotetext{
30 Vid. Martínez-Gijón Machuca, El seguro de asistencia sanitaria, cit., pp. 21-22. También, Tirado SuÁrez. Los seguros de personas, cit., p. 205.

31 Vid. Martín Casals/Ribot Igualada/Solé Feliú. La responsabilidad de las entidades de seguros de salud en las reclamaciones judiciales por errores o negligencias médicas, cit., p. 12. SÁNCHEZ CALERO. Comentario al artículo 105 LCS, $4^{\mathrm{a}}$ ed., cit., pp. 2690-2691.

32 CARbajo CASCón. La responsabilidad civil del asegurador de asistencia sanitaria, cit., pp. 97 y ss.

33 Vid. Marco Arcalá. Seguros de personas. Aspectos generales, cit., p. 55, con cita de doctrina y jurisprudencia.
} 
ese tipo. En los seguros de salud la enfermedad actúa como riesgo genérico o riesgopresupuesto; pero en las distintas modalidades de seguros de salud el riesgo cubierto en el contrato de seguro no es la enfermedad en sí misma, sino las consecuencias concretas que produce la enfermedad y que constituyen la causa o fin concreto por el que se llega a celebrarse el contrato de seguro. De modo tal que, si llega a producirse la enfermedad, concebida como riesgo genérico o riesgo-presupuesto, nace o se verifica un riesgo específico de segundo grado relacionado con esa alteración en el estado de salud (riesgo concreto), distinto en cada modalidad de contrato de seguro de enfermedad lato sensu, el cual actúa como presupuesto causal de cada tipo contractual y en cuyo aseguramiento o garantía de cobertura por el asegurador se centra el interés del asegurado. Así, en el seguro de enfermedad consistente en la entrega de un capital, en forma de sumas o rentas, el riesgo reside en el perjuicio económico (en forma de lucro cesante) que la enfermedad -si llega a verificarse- produciría en el patrimonio del asegurado, al no poder atender sus obligaciones laborales o profesionales. En el seguro de enfermedad en forma de reembolso de gastos médicos y farmacéuticos, de naturaleza indemnizatoria, el riesgo consiste en el perjuicio económico (en forma de daño emergente) que el estado de enfermedad - de constatarse- produciría en el patrimonio del asegurado al tener que hacer frente por sí mismo a los gastos de asistencia médica y farmacéutica ${ }^{34}$. No es tan fácil, sin embargo, delimitar el riesgo e interés asegurados en el seguro de asistencia sanitaria, pues depende de si la obligación de cobertura del asegurador se califica como una prestación indemnizatoria del coste de los gastos de asistencia médica y farmacéutica (similar a la del seguro de reembolso de gastos sanitarios) o bien como una prestación de servicios sanitarios o asistencial.

Un relevante sector de nuestra doctrina, defiende que en el seguro de asistencia sanitaria el asegurador no se compromete a prestar o ejecutar "directamente" servicios sanitarios (como erróneamente sugiere el art. 105 LCS), sino que la prestación de la entidad aseguradora consiste en la organización y gestión de los medios materiales para hacer posible la provisión de servicios de salud, garantizando la disponibilidad de los profesionales o centros necesarios en las condiciones establecidas en el contrato de seguro y asumiendo directamente el costo de la prestación de tales servicios ${ }^{35}$. De modo que, tanto en el seguro de enfermedad de reembolso de gastos como en el seguro de asistencia sanitaria, "el asegurador asume el precio de la prestación de esos servicios, en lugar del asegurado y en las condiciones establecidas en el contrato de seguro, si bien en el primer caso el asegurador abona determinadas sumas al asegurado y en el segundo efectúa el pago directamente a quien presta el servicio médico, quirúrgico y farmacéutico" ${ }^{\text {". }}$. Por lo tanto, de acuerdo con esta tesis, el riesgo cubierto por los distintos seguros de enfermedad, tanto en la modalidad de seguros de sumas, como de reembolso de gastos y de asistencia sanitaria, consiste en el interés que

\footnotetext{
${ }^{34}$ La STS (Sala $1^{\text {a }}$ ) de 13 de julio de 2002 (RJ 202/5910) señala que en un contrato de seguro donde la aseguradora se compromete a hacerse cargo de los gastos de asistencia sanitaria derivados de enfermedades diagnosticadas o accidentes sufridos dentro del periodo de vigencia de la póliza, "el riesgo cubierto no es la enfermedad en sí misma, sino el gasto devengado durante la vigencia de la póliza como consecuencia de la dolencia o accidente acaecido durante el periodo en que el contrato estaba en vigor" (Fdto. Dcho $4^{\circ}$ ).

35 Cfr., Sánchez Calero. Comentario al artículo 105 LCS, $4^{\mathrm{a}}$ ed., cit., pp. 2690 y 2702-2703.

36 Martín Casals/Ribot Igualada/Solé Feliú. La responsabilidad de las entidades de seguros de salud en las reclamaciones judiciales por errores o negligencias médicas, cit., p. 13.
} 
tiene el asegurado en asegurarse frente a las consecuencias económicas de un estado de enfermedad que puede ocasionarle gastos médicos, farmacéuticos o de asistencia ${ }^{37}$. Se apunta en esta línea que "en el seguro de asistencia sanitaria el asegurado tiene interés en preservar la salud (y, por consiguiente, está interesado en que el riesgo -las enfermedades o lesiones- no se produzca) no tanto porque la salud permite al asegurado desarrollar una actividad diaria normal y, por ende, realizar su actividad laboral con el consiguiente resultado económico, sino especialmente porque de este modo se evita un daño económico en su patrimonio" 38 . De modo que, según esta tesis, el interés del asegurado consiste en evitar un daño patrimonial, ya que se produciría un menoscabo en su patrimonio si pretendiera acceder a las mismas prestaciones médicas, quirúrgicas y hospitalarias sin haber contratado un seguro; desplegando así la misma función que algunos seguros contra daños, como el de responsabilidad civil y el de defensa jurídica. Entonces, lo que caracterizaría a este seguro respecto al seguro de enfermedad en la modalidad de reembolso de gastos, es que el importe de la reparación de la salud, correspondiente a los gastos derivados de la asistencia sanitaria necesaria, no ingresa en el patrimonio del asegurado, ya que no es éste quien asume el coste, sino la compañía aseguradora; de lo cual deduce una cierta finalidad preventiva de un daño económico en la contratación del seguro de asistencia sanitaria ${ }^{39}$. De modo que: "en la modalidad de prestación de servicios (sin reembolso de gastos) predomina la función preventiva del seguro, que se contrata para evitar un posible menoscabo económico, y en la modalidad de asistencia sanitaria con restitución de los gastos médicos predomina la función indemnizatoria de un daño efectivamente producido en el patrimonio del asegurado"40. Estaríamos hablando así de un seguro de daños en el patrimonio que cumpliría una función preventiva del daño económico que la enfermedad podría causar en el patrimonio del asegurado si tuviera que afrontar con sus propios medios el coste de la asistencia sanitaria.

Personalmente no comparto esta construcción de la estructura del seguro de asistencia sanitaria como seguros de daños en el patrimonio con vocación preventiva, la cual considero sumamente condicionada por la concepción clásica de conceptos

\footnotetext{
37 Garrigues. Contrato de seguro terrestre..., cit., p. 645. Martín Casals/Ribot Igualada/Solé Feliú. La responsabilidad de las entidades de seguros de salud en las reclamaciones judiciales por errores o negligencias médicas, cit., pp. 13-14.

38 MartíneZ-Gúón MachuCA. El seguro de asistencia sanitaria, cit., p. 27.

39 De esta forma se relaciona el seguro de asistencia sanitaria con las prestaciones de reparación o prestaciones en especie permitidas por el art. 18 II LCS, entendiendo que la prestación de servicios sanitarios sin desembolso previo por el asegurado constituye una forma de indemnizar al asegurado en especie, mediante la reparación del objeto siniestrado que sería la salud del asegurado. Así, también, Martín CASAls/Ribot Igualada/Solé Feliú. La responsabilidad de las entidades de seguros de salud en las reclamaciones judiciales por errores o negligencias médicas, cit., p. 14. Asimismo, se afirma para el seguro de dependencia que la indemnización no ingresa en el patrimonio del tomador, sino que los asume como obligación de hacer la aseguradora (art. 18 II LCS). Cfr., VeIGA Copo, El seguro de dependencia, cit., p. 150. Interpretación que no convence demasiado, siquiera sea porque no casa demasiado bien defender que el riesgo e interés asegurados están en el patrimonio del asegurado frente al menoscabo patrimonial que supone la asistencia sanitaria, y señalar al mismo tiempo que la prestación del asegurador no es indemnizatoria pecuniaria, sino de reparación...del cuerpo humano, de la salud; cuando el daño se produciría realmente en el patrimonio como consecuencia de la enfermedad.

40 Martínez-Gijón Machuca. El seguro de asistencia sanitaria, cit., p. 30.
} 
tradicionales del derecho del seguro, sea por la clasificación de los seguros en dos grandes grupos de riesgos (daños y personas) o sea por el concepto economicista de interés. A mi juicio, la prestación del asegurador de asistencia sanitaria es una prestación asistencial o de servicios, no una prestación indemnizatoria -ni siquiera entendida como prestación de reparación de carácter preventivo-del coste patrimonial que conllevan los gastos de asistencia médica, quirúrgica y hospitalaria; sin perjuicio de que la asistencia, la prestación del servicio por el asegurador, evite al asegurado tener que asumir ese coste, que, quizás - pero sólo quizás- no estaría en condiciones de poder realizar ${ }^{41}$.

En los seguros asistenciales el evento asegurado es un evento fortuito - entendido como verificación de un riesgo- que crea una situación de dificultad de la cual surge la necesidad de una ayuda o asistencia inmediata, la cual puede consistir en una prestación en dinero (prestación de dar) o en especie (prestación de hacer) ${ }^{42}$; aunque sin duda, es la prestación de servicios lo que caracteriza principalmente a los seguros de asistencia. El riesgo concreto lo constituye la situación de necesidad producida por la verificación del evento fortuito, la cual requiere una ayuda inmediata. Aunque concurre normalmente un eventual daño económico en el patrimonio, no considero que constituya el factor fundamental, sino más bien accesorio. Lo decisivo es la necesidad de ayuda o asistencia asociada a la situación de dificultad, lo cual no empecé que esa situación de necesidad derive de un daño: la particularidad estriba en que el daño no asume relevancia por sí mismo como riesgo cubierto o asumido por el asegurador, sino que es el presupuesto que provoca la situación de necesidad que requiere ayuda inmediata, la cual constituye el riesgo asegurado en el contrato de seguro de asistencia $^{43}$. En estos seguros asistenciales el componente esencial de la prestación del asegurador es la ayuda o asistencia inmediata al asegurado mediante la prestación de los servicios comprometidos en la póliza. El fin del contrato (causa-función) no es el reembolso de gastos asumidos por el asegurado, ni tampoco solamente el pago del coste de la asistencia; esto es, la mera eliminación o reducción del precio o coste de la asistencia sanitaria que, de otro modo, tendría que afrontar el asegurado por sus propios medios. El fin del contrato es procurar al asegurado el acceso inmediato a los servicios necesarios para atender la necesidad creada tras la verificación del evento fortuito $^{44}$, permitiéndole disfrutar de servicios médicos que, de otra forma, no podría costearse por sí sólo. El riesgo está -insisto- en la situación de necesidad derivada del evento fortuito y el interés en la obtención inmediata de la asistencia necesaria para neutralizar la enfermedad, para lo cual el asegurador tendrá que haber organizado previamente una estructura asistencial adecuada para la prestación de los servicios comprometidos en la póliza, sea propia y/o concertada con terceros. Naturalmente el asegurado persigue también con este tipo de seguro obtener una asistencia sanitaria

\footnotetext{
${ }^{41}$ Carbajo Cascón. La responsabilidad civil del asegurador de asistencia sanitaria, cit., pp. 137 y ss.

${ }_{42}$ Así lo dispone expresamente el art. 1.2 II de la primera Directiva no vida 73/239/CEE, en la redacción dada por el art. 1 de la segunda Directiva no vida 84/641/CEE. También el art. 2.2 de la Directiva 2009/138/ $\mathrm{CE}$, de 25 de noviembre, que deroga las anteriores.

43 Vid. ampliamente, en Gianguido SCALFI, L'assicurazione tra rischio e finanza, Giuffrè, Milano, 1992, pp. 14-15. También en Giovanna Volpe Putzolu. "Prestazione di servizi nell'evoluzione del rapporto assicurativo", en Assicurazioni, 2000-I, pp. 7 y ss.

44 Cfr., Volpe Putzolu. "Prestazione di servizi nell'evoluzione del rapporto assicurativo", cit., p. 16.
} 
lo más amplia posible y diluir el coste propio o de mercado de los servicios sanitarios en su patrimonio, mediante el pago de una prima o cantidad periódica al asegurador de asistencia sanitaria que se compromete a proporcionarle esos servicios de forma inmediata, despreocupándose por completo del coste de tales servicios que asume directamente el asegurador. De modo que el asegurado tendría interés en evitar un daño en su patrimonio: el coste o precio de mercado de los servicios médicos, quirúrgicos, de diagnóstico y hospitalarios. Considero, no obstante, que ese interés preventivo de un coste o gasto patrimonial sólo puede considerarse como un interés accesorio o complementario, en todo caso secundario, del interés principal o fundamental del asegurado: la obtención inmediata de asistencia sanitaria lo más amplia posible por el tomador o por un tercero asegurado (un familiar, un empleado, etc., en situaciones típicas de seguros de grupo) caso de producirse la enfermedad.

En el seguro de asistencia sanitaria el asegurado busca de manera preferente o prioritaria la prestación de los servicios médicos y hospitalarios que sean necesarios para neutralizar cualquier alteración de su salud, sin perjuicio de que persiga también evitarse molestias en la búsqueda y contratación de esos servicios en situaciones para él difíciles o simplemente incómodas, así como obtener indirectamente un ahorro en la adquisición o disfrute de esos servicios respecto al precio normal de mercado de los mismos que, seguramente, de no estar asegurado, podría no poder afrontar con sus propios medios económicos. El asegurado busca la asistencia sanitaria inmediata, porque eso le ahorra situaciones de angustia (tener que buscar médicos, clínicas u hospitales cuando está confuso o preocupado al comprobar la alteración en su estado de salud) o simplemente molestias (tener que buscar médicos, clínicas u hospitales si, por ejemplo, se encuentra desplazado fuera de su domicilio habitual o si no conoce ningún facultativo que pueda tratar su dolencia en su propia ciudad, además de situaciones de emergencia atendidas domiciliariamente), sabiendo además que podrá disfrutar de una amplia cobertura asistencial sin tener que realizar un desembolso económico previo (o bien realizando un desembolso mínimo si en el contrato se hubieran pactado franquicias para todos o algunos servicios sanitarios); lo cual no significa necesariamente que el asegurado no tenga capacidad para afrontar personalmente el coste de la asistencia ${ }^{45}$, aunque muy probablemente no dispondría de la liquidez suficiente para afrontar todos los servicios diagnósticos, tratamientos médicos y servicios hospitalarios que le ofrece el asegurador.

Puede decirse, en suma, que el riesgo de menoscabo patrimonial y el valor económico atribuible en su caso a la necesidad de asistencia inmediata en situaciones de necesidad, así como el interés consistente en la obtención de una asistencia sanitaria amplia asumida directamente por el asegurador y en el coste económico que podría asociarse al hecho de tener que buscar y contratar por sí solo servicios sanitarios en situaciones de desamparo, confusión y angustia, tienen un carácter accesorio y

\footnotetext{
${ }^{45}$ De hecho, en los seguros privados de asistencia sanitaria no se suelen incluir los costes derivados de la adquisición de fármacos necesarios para tratar la dolencia. Si el seguro de asistencia sanitaria se concierta a través de la Mutualidad de Funcionarios del Estado (MUFACE), es ésta mutualidad y no la entidad aseguradora que provee los servicios sanitarios la que se hace cargo de parte del coste farmacéutico mediante talonarios de recetas entregados a sus mutualistas donde los facultativos de la aseguradora pueden expedir recetas.
} 
secundario respecto al riesgo e interés principales o fundamentales que actúan como presupuestos del contrato de seguro de asistencia sanitaria: la situación de necesidad creada por la enfermedad y la garantía o seguridad que, en términos de bienestar, aporta la asistencia sanitaria inmediata y con una cobertura lo suficientemente amplia para el tratamiento de la misma. La moderna literatura económica, pone de manifiesto que, aunque efectivamente el sistema del seguro privado de salud permite una reducción de precios $\mathrm{y}$, con ello, evitar un menoscabo patrimonial, la verdadera finalidad del seguro consiste en la utilidad, en el bienestar que produce la posibilidad de disfrutar de unos servicios médicos y hospitalarios amplios que podrían ser inalcanzables para el asegurado de no haber concertado la póliza correspondiente. Se ha señalado, en este sentido, que la obtención de servicios de salud no puede medirse exclusivamente en términos de precios (pagar menos por los servicios médicos) o en términos estrictamente financieros (evitar la pérdida patrimonial que supone tener que abonar directamente los servicios sanitarios en caso de enfermedad), sino que debe buscarse la función de utilidad asociada a los mismos; en concreto, la expectativa de la asistencia sanitaria creada por el seguro, que permite disfrutar de un mejor cuidado médico y hospitalario en caso de caer enfermo del que podría permitirse el asegurado si no hubiera concertado la póliza ${ }^{46}$.

\section{ALCANCE DE LA COBERTURA COMPROMETIDA POR EL ASEGURADOR: ¿GARANTIZA EL ASEGURADOR LA CORRECTA EJECUCIÓN DE LOS SERVICIOS SANITARIOS?¿DEBE RESPONDER POR LAS NEGLIGENCIAS DE SU CUADRO MÉDICO Y HOSPITALARIO?}

\section{Consideraciones previas}

La compleja estructura de la prestación del asegurador de asistencia sanitaria no supone una variación en la consideración de la prestación general de garantía o seguridad como una obligación de resultado. Desde la perspectiva general de los seguros asistenciales o de prestación de servicios, dado que las prestaciones intermedia o instrumental -de organización de medios técnicos y humanos- y final o material -ejecución o prestación efectiva de los servicios- tienen un carácter accesorio o secundario respecto a la prestación general o abstracta de seguridad o garantía frente a una eventual situación de necesidad, la doctrina científica afirma que la entidad aseguradora asume en todo caso una obligación de resultado, consistente en el ofrecimiento -también psicológicode seguridad o garantía, que se hace extensiva a las obligaciones derivadas de las prestaciones accesorias; y ello aunque la prestación material concreta consista en una obligación de hacer o prestar un servicio (y por lo tanto, normalmente, obligación de medios), ya que esta obligación tiene en todo caso un carácter instrumental para, en

${ }^{46}$ Cfr., John A. Nyman. The Theory of Demand for Health Insurance, Stanford University Press, California, 2003, pp. 30, 103, 118, 164-165. 
el caso concreto de que se verifique el evento fortuito, procurar la obtención por el asegurado del resultado de seguridad que perseguía al celebrar el contrato de seguro ${ }^{47}$.

De acuerdo con este esquema, además de garantizar el acceso inmediato o dentro de un lapso temporal razonablemente breve a un elenco plural, diverso, equilibrado y de calidad de profesionales y centros sanitarios, el asegurador de asistencia sanitaria debería también garantizar el resultado final querido por el asegurado. En consecuencia, el incumplimiento o el cumplimiento defectuoso de las obligaciones organizativas y asistenciales inherentes a la prestación general de cobertura sanitaria propia del seguro de asistencia sanitaria, con niveles razonables de amplitud y calidad, podría derivar en responsabilidad del asegurador por incumplimiento de la obligación de resultado. Pero la cuestión clave está en delimitar si ese resultado, esa cobertura querida por el asegurado, consiste en la seguridad o garantía de disponer de acceso inmediato o a un plazo razonable a unos servicios de asistencia sanitaria lo suficientemente amplios, diversos y equilibrados para el tratamiento de la enfermedad en régimen de libre elección; o si el resultado garantizado por el asegurador y perseguido por el asegurado se extiende al disfrute de servicios idóneos, plurales y de calidad, incluyendo la correcta ejecución de los mismos, resultando responsable de los daños y perjuicios que -en su caso- pudiera sufrir el asegurado como consecuencia de servicios médicos, clínicos y hospitalarios defectuosos por parte de los facultativos y centros -propios y ajenos- integrados en el cuadro asistencial del asegurador; aceptando, en este segundo caso, la premisa de que el daño provocado por la actuación culposa o negligente del facultativo o centro hospitalario integrado en el cuadro médico del asegurador supone un incumplimiento contractual del asegurador al verse defraudadas las expectativas legítimas (de idoneidad y calidad del servicio, de correcta prestación del mismo etc.) del asegurado cuando contrató ese seguro.

Aunque la obligación genérica de cobertura asistencial del asegurador constituya una obligación de resultado que se extiende también a las obligaciones secundarias de organización y efectiva prestación de servicios médicos, clínicos y hospitalarios, entiendo que la misma no debería alcanzar nunca el resultado final; esto es, el asegurador de asistencia sanitaria no puede resultar obligado a garantizar la curación o sanación del asegurado, en tanto en cuanto ni siquiera los propios profesionales y centros sanitarios pueden comprometerse a ese resultado.

No obstante, para la Jurisprudencia y parte de la doctrina científica existen argumentos de peso para afirmar que el asegurador sí que puede y debe garantizar una cobertura de calidad y, por tanto, la correcta ejecución de los servicios sanitarios concretos prestados por los facultativos y centros integrados en su cuadro asistencial; ya pertenezcan a su propia estructura empresarial o ya se trate de profesionales y centros independientes. De modo que el asegurador resultaría responsable no sólo en casos de falta de medios

\footnotetext{
${ }^{47}$ Para ScAlFi. L'Assicurazione tra rischio e finanza, cit., p. 14, la configuración de la prestación general de garantía del asegurador como una obligación de resultado no choca con el contenido de la prestación concreta o material - caso de producirse el siniestro- como una obligación de hacer mediante la prestación de un servicio. Vid. también, DAmIANI. Contratto di assicurazione e prestazione di sicurezza, cit., pp. 147 y 149, quien apunta que la prestación in natura (servicios) constituye sólo una actividad instrumental para alcanzar el resultado de certeza o seguridad perseguido ab initio por el asegurado.
} 
humanos y materiales suficientes para atender holgadamente las necesidades de asistencia de los asegurados (falta de asistencia o retraso injustificado en la prestación de servicios sanitarios incluidos en la póliza) o de la negativa a prestar la asistencia requerida (si no se basa en algún motivo expresamente previsto en la póliza bien como cláusula delimitadora o limitativa del alcance del seguro), sino también cuando una mala prestación de esos servicios derive en daños y perjuicios para los asegurados (incorrecta ejecución del servicio sanitario que presume la falta de calidad del mismo y el incumplimiento del asegurador que garantiza servicios sanitarios de calidad).

\section{Doctrina jurisprudencial sobre la responsabilidad del asegurador de asistencia sanitaria}

A partir de aquí es preciso delimitar diferentes situaciones:

i) Cuando los asegurados acuden a centros sanitarios titularidad de la misma entidad aseguradora y padecen daños o perjuicios por el funcionamiento defectuoso del servicio sanitario o por negligencias o errores de los facultativos que trabajan en dichos centros, existen varios argumentos para reconocer la responsabilidad civil de la entidad aseguradora en tanto que titular del centro y empleadora de los profesionales que en el mismo trabajan. En este caso la compañía tendrá la doble condición de aseguradora de asistencia sanitaria y prestadora efectiva y directa de servicios sanitarios.

La responsabilidad de la compañía aseguradora en estos casos puede fundarse en la responsabilidad civil extracontractual por hecho ajeno ex art. 1903.4 CC por culpa in eligendo o culpa in vigilando de la aseguradora respecto a la actuación de los profesionales que trabajan en los centros sanitarios de su titularidad, sea en régimen laboral, de servicios o de obra o fruto de cualquier otro vínculo. También puede fundarse en la responsabilidad contractual de la aseguradora por los actos cometidos por sus auxiliares contractuales, la cual, aunque carece de reconocimiento expreso en nuestro ordenamiento jurídico ha sido consagrada como lícita y posible por la Jurisprudencia y la doctrina científica, extrayéndola por analogía de la responsabilidad extracontractual de los empresarios por hechos de sus auxiliares y dependientes por culpa in eligendo o culpa in vigilando, o bien deduciéndola del viejo brocardo "Cuius est commodum eius est periculum", esto es, quien se beneficia de una actividad ajena debe soportar el perjuicio causado por la misma (STS de 1 de marzo de 1990). Finalmente, podría imputarse responsabilidad a la aseguradora recurriendo a la responsabilidad objetiva en defensa de los consumidores y usuarios de servicios sanitarios, prevista en el art. 148, II TRLGDCU 2007, la cual no afecta a los actos médicos propiamente dichos, sino únicamente a los aspectos organizativos de la prestación de servicios sanitarios, por lo que sólo puede dirigirse contra las personas físicas o jurídicas titulares de centros médicos y hospitalarios, y además no se puede realizar de forma automática, sino -en necesaria conexión con el apartado I del mismo precepto- sólo cuando el servicio sanitario causante de daños se haya prestado de forma anómala y siempre que esos servicios incluyan una garantía de pureza, eficacia y seguridad, de modo que sea el incumplimiento de esos niveles lo que determine la responsabilidad (SSTS de 26 de marzo de 2004, 5 de enero de 2007 y 24 de mayo de 2012). 
ii) Más dudoso es que la compañía aseguradora tenga que responder de los daños provocados por negligencias médicas u hospitalarias de centros y profesionales independientes concertados mediante contratos de servicios para prestar asistencia sanitaria a sus asegurados, toda vez que no están integrados en su estructura empresarial y es el usuario del seguro quien libremente elige acudir a un concreto centro o profesional de los que ofrece el asegurador en su cuadro médico. Sin embargo, así lo viene admitiendo nuestra Jurisprudencia en la última década, sobre la base de diferentes argumentos entre los que destaca la valoración que se hace sobre la naturaleza de la prestación del asegurador de asistencia sanitaria.

Desde la STS de 12 de febrero de 1990 y las posteriores de 2 de noviembre de 1999, 10 de noviembre de 1999, 19 de junio de 2001, 4 de octubre de 2004, 17 de noviembre de 2004, 21 de junio de 2006 y 8 de noviembre de 2007, el Alto Tribunal empleó diferentes argumentos hermenéuticos para imputar a la aseguradora la responsabilidad civil por los daños causados a sus asegurados por profesionales y centros independientes incluidos en su cuadró médico-asistencial, recurriendo a la responsabilidad extracontractual por hecho ajeno, la responsabilidad contractual por actos de los auxiliares contractuales, y en algunas ocasiones, con carácter accesorio o complementario, la responsabilidad objetiva por el funcionamiento defectuoso de servicios sanitarios. Las fundamentales SSTS de 4 de diciembre de 2007 y -sobre todo- de 4 de junio de 2009, continuadas luego por las SSTS de 4 de noviembre de 2010, 16 de enero de 2012 y 24 de mayo de 2012 (así como las posteriores, SSTS de 20-1-2017, 29-4-2021, 19-7-2021), presentan de forma unitaria y sintetizan la doctrina del Tribunal Supremo mostrando al asegurador de asistencia sanitaria como garante del servicio sanitario prestado por los centros y facultativos incluidos en su cuadro médico, reforzado además por la concurrencia del principio de apariencia y de actos de publicidad que integran la oferta contractual de las compañías de este sector, y entendiendo que la aseguradora impone los profesionales aunque sea en forma plural, al no permitir al asegurador elegir fuera del cuadro asistencial, de lo cual deduce una relación de dependencia que justifica tanto la responsabilidad extracontractual por hecho ajeno como la responsabilidad contractual por actos de los auxiliares.

Resultan especialmente significativas las afirmaciones que realiza el Tribunal Supremo en su Sentencia de 4 de junio de 2009 en defensa de su doctrina jurisprudencial imputando responsabilidad a las compañías aseguradoras de asistencia sanitaria, cuando indica que: “...la función del asegurador no es la de facilitar cuadros médicos, clínicas, enfermeras, o centros de diagnóstico mencionados en sus cuadros clínicos, sino la de asumir directamente la prestación del servicio, y garantizar la corrección e idoneidad de los medios personales y materiales empleados..."; que "( $L)$ a obligación del asegurador no termina con la gestión asistencial, sino que va más allá, en atención a la garantía de la calidad de los servicios que afectan al prestigio de la compañía y consiguiente captación de clientela"; y que el contrato de seguro "no se limita a cubrir los daños que se le producen al asegurado cuando tiene que asumir los costes para el restablecimiento de su salud, sino que se dirige a facilitar los servicios sanitarios incluidos en la Póliza a través de facultativos, clínicas e instalaciones adecuadas, conforme resulta del artículo 105 de la Ley del Contrato de Seguro, con criterios de selección que se desconocen, más allá de lo que exige 
la condición profesional y asistencial que permite hacerlo efectivo, que impone la propia aseguradora para ponerlos a disposición del paciente al que se le impide acudir a un profesional o centro hospitalario distinto y que puede resultar defraudado por una asistencia carente de la diligencia y pericia debida por parte de quienes le atienden" (Fdto. Dcho. $2^{\circ}$ ). Y frente a las críticas vertidas por una parte relevante de la doctrina científica y por el propio sector asegurador del ramo, concluye que: " $Y$ si bien es cierto, como apunta algún sector de la doctrina, que posiblemente sería necesaria una mejor delimitación de los artículos 105 y 106 de la LCS, que estableciera el alcance de las respectivas obligaciones de las partes y su posición frente a los errores médicos y hospitalarios, también lo es que la redacción actual no permite otros criterios de aplicación que los que resultan de una reiterada jurisprudencia de esta Sala sobre el contenido y alcance de la norma y la responsabilidad que asumen las aseguradoras con ocasión de la defectuosa ejecución de las prestaciones sanitarias por los centros o profesionales, como auxiliares de las mismas en el ámbito de la prestación contractualmente convenida, en unos momentos en que la garantía y calidad de los servicios mediante sus cuadros médicos se oferta como instrumento de captación de la clientela bajo la apariencia y la garantía de un servicio sanitario atendido por la propia entidad" (Fdto. Dcho $1^{\circ}$ ).

De esta forma, la Sala Primera del Tribunal Supremo asume que el asegurado de asistencia sanitaria perjudicado por negligencias médicas o asistenciales de los profesionales independientes incluidos en el cuadro médico ofrecido por la compañía aseguradora, podrán exigir responsabilidad a esta recurriendo a distintos criterios de imputación (extracontractuales o contractuales), incluso acumulables, aunque opta claramente de forma preferencia por el criterio de la responsabilidad contractual por actos de los auxiliares. El Tribunal interpreta la prestación asistencia comprometida por el asegurador como una prestación efectiva, eficaz y de calidad de servicios sanitarios, convirtiéndose en un garante del servicio sanitario ofrecido y no en un mero facilitador o intermediario, toda vez que la garantía y calidad de los servicios mediante sus cuadros médicos se oferta como instrumento de captación de la clientela bajo la apariencia y la garantía de un servicio sanitario atendido por la propia entidad.

Se establece así la responsabilidad de la compañía aseguradora basada en la forma de actuación de los facultativos en virtud del principio de apariencia que otorga el ofrecimiento de la asistencia por la aseguradora y de la publicidad que ésta realiza, los cuales integran el contenido del contrato con arreglo a la legislación de consumidores. Considera el Tribunal, también, que la responsabilidad deriva de la existencia de una intervención directa de la aseguradora en la elección de los facultativos, que actuarían así como auxiliares de la compañía en al ámbito de la prestación contractualmente convenida, siendo limitada la libertad de elección de los asegurados. Los facultativos y centros seleccionados por la compañía aseguradora tendrían así una posición de subordinación contractual (fundada entre ambos en un contrato a favor de terceros), siendo auxiliares en la prestación de servicios ofrecidos y garantizados por el asegurador, debiendo asumir la aseguradora los daños y perjuicios derivados de la actuación de dichos auxiliares según la regla "cuius est commodum eius est periculum (incommoda)". 
Se establece, en definitiva, de forma implícita, un régimen de solidaridad impropia, en el que la responsabilidad extracontractual o contractual de la entidad aseguradora (criterio de imputación directa $\mathrm{u}$ objetiva) no excluye la posible responsabilidad del facultativo o centro sanitario frente al paciente asegurado, no siendo posible invocar la excepción de falta de litisconsorcio pasivo necesario, y sin perjuicio de la acción de regreso o repetición del asegurador contra los auxiliares responsables últimos del daño causado a los asegurados (cfr. SSTS de 13 de abril de 2016, 20 de enero de 2017, 20 de septiembre de 2018, 22 de enero de 2020 y 29 de abril de 2021). Solidaridad impropia basada no tanto en una causación simultánea del daño, sino más bien en la concurrencia causal (indirecta) en la producción, fundada en la doctrina de la causa adecuada o de la causa eficiente.

Por lo demás, el Tribunal Supremo tiene declarado que resultan aplicables al asegurador de asistencia sanitaria -que resulte responsable solidario de los daños causados por los facultativos y centros sanitarios que prestan de forma efectiva los servicios comprometidos en la póliza los intereses moratorios del artículo 20 LCS (SSTS de 6 de febrero de 2018, 22 de octubre de 2019, 9 de junio de 2020 y 5 de octubre de 2020).

Alega el Tribunal que la STS de 4 de junio de 2009 ya impuso los intereses moratorios, desde la fecha de interposición de la demanda, porque: i) "los defectos de cumplimiento se transmutan en una prestación indemnizatoria de los daños y perjuicios, cumplimiento por equivalencia con naturaleza de deuda de valor, que se paga en dinero, y el interés abarca todas las prestaciones del asegurador", y; ii) "la Sala ha seguido una línea interpretativa caracterizada por un creciente rigor en atención al carácter sancionador que cabe atribuir a la norma". A mayor abundamiento, considera que deben imponerse los intereses penalizadores porque el asegurado sólo podía elegir libremente para su asistencia a cualquiera de los médicos que realizan las prestaciones sanitarias incluidas en la póliza dentro del catálogo de servicios ofrecido por la aseguradora.

La STS de 6 de febrero de 2018 tenía el voto particular del Excmo Sr. Antonio Salas Carceller, quien consideró que la responsabilidad por hecho de otro no ha de quedar sujeta a lo dispuesto por el artículo 20 LCS, que sanciona exclusivamente la mora por parte de la aseguradora en el cumplimiento de las obligaciones derivadas directamente del contrato de seguro, al entender que se trata de una norma excepcional que, en parte tiende a la actualización de la cantidad debida, pero sobre todo a sancionar un incumplimiento contractual imputable a la aseguradora, que se obligó a realizar determinada prestación a cambio del cobro de una prima y, surgida su obligación, deja de cumplir en tiempo. Esto es, el voto particular diferencia entre incumplimiento de la prestación de servicios asistenciales comprometida por el asegurador, consistente en poner a disposición un cuadro médico suficiente para la asistencia requerida, y la responsabilidad por relación causal indirecta derivada de una negligencia médica de profesionales que actúan sin control alguno ni instrucciones de la aseguradora, entendiendo que el artículo 20 LCS ha de ser de interpretación restrictiva, como norma sancionadora y excepcional, y que por lo tanto no debe ser aplicada más allá de su estricta finalidad a casos donde la responsabilidad de la aseguradora sería en todo caso indirecta. 


\section{CRÍTICA DE LA DOCTRINA JURISPRUDENCIAL Y PROPUESTA DE REVISIÓN}

La primera crítica a la doctrina firme del Tribunal Supremo reside en la calificación de la prestación del asegurador, que la mayoría de nuestra doctrina científica considera de naturaleza indemnizatoria del menoscabo que para el patrimonio del asegurado supone tener que afrontar con sus propios medios los gastos de asistencia sanitaria consecuentes a la enfermedad. Así, se alega que la aseguradora se limitaría a organizar los medios personales y materiales para prestar asistencia sanitaria a sus asegurados y a gestionar los medios financieros (las primas recibidas de los asegurados) para financiar el coste de esos servicios repartiendo el riesgo entre muchos asegurados ${ }^{48}$. A partir de aquí, se critica la inexactitud y falta de rigor de la doctrina jurisprudencial al aplicar la responsabilidad civil extracontractual por hecho ajeno y la responsabilidad contractual del asegurador por actos de sus auxiliares, además -en su caso- de la responsabilidad objetiva de la normativa de tutela de consumidores, sin tener en cuenta que el ámbito de las obligaciones y por tanto de responsabilidad del asegurador, por un lado, y de centros y profesionales sanitarios, por otro, son totalmente diferentes, en la medida en que el asegurador otorga a los asegurados la facultad de libre elección de centros y profesionales entre los que figuran en su cuadro médico, concertándose luego un contrato de servicios entre centro o médico y asegurado de cuyas consecuencias (de los daños causados por una mala praxis profesional) no puede hacerse cargo el asegurador en ningún caso ${ }^{49}$.

Sin embargo, se ha podido apreciar que el Tribunal rechaza frontalmente la consideración indemnizatoria del seguro de asistencia sanitaria como un seguro de daños en el patrimonio del asegurado, como patrocina una parte apreciable de la doctrina científica. Antes bien, confirma la consideración de este seguro como un seguro asistencial o de prestación de servicios, que compartimos plenamente. Sin embargo, en los argumentos empleados por el Tribunal Supremo en su doctrina sobre este punto (seguida de manera casi unánime por la jurisprudencia de las Audiencias Provinciales y Juzgados de Primera Instancia) $)^{50}$, se respira con fuerza un claro sentimiento o intención pro consumatore, dada la importancia de los intereses presentes en la relación contractual del seguro de asistencia sanitaria y ante la insuficiencia, en muchas ocasiones, de las pólizas de responsabilidad civil obligatorias de los profesionales y centros sanitarios para satisfacer las indemnizaciones correspondientes

\footnotetext{
48 Vid. VÁzQuez de PAdura. "La responsabilidad ante el paciente de las entidades de seguro de asistencia sanitaria", cit., pp. 848-850.

49 Martín Casals/Ribot Igualada/Solé Feliú. La responsabilidad de las entidades de seguros de salud en las reclamaciones judiciales por errores o negligencias médicas, cit., pp. 41 y ss. Los mismos argumentos se encuentran también en Miquel MarTín CASALS. "Líneas generales sobre la responsabilidad de las entidades de seguros de salud en las reclamaciones por efectos adversos, errores o negligencias médicas", RES 2006, n 128, pp. 803 y ss.

50 Entre otras muchas, SAP Madrid, Secc. 14 $4^{\mathrm{a}}$, de 5 de mayo de 2004; SAP Baleares, Secc. $5^{\mathrm{a}}$, de 5 de julio de 2006; SAP Valencia, Secc. $8^{\text {a }}$, de 30 de junio de 2008; SAP Tarragona, Secc. $1^{\text {a }}$, de 22 de diciembre de 2010; SAP Valencia, Secc. 11 ${ }^{\mathrm{a}}$, de 30 de diciembre de 2010.
} 
a una mala praxis profesional ${ }^{51}$. Esto es, la defensa del usuario de seguros ("in dubio pro asegurado" $)^{52}$ se convierte en muchas ocasiones en elemento determinante de la doctrina jurisprudencial, condicionando la decisión sobre el contenido y alcance que debe atribuirse a la prestación del asegurador de asistencia sanitaria, y aplicando los criterios propios de la responsabilidad civil extracontractual, contractual y objetiva, sin examinar a fondo si concurren las circunstancias necesarias para su aplicación al caso concreto a la vista de la estructura y finalidad última del contrato de seguro de asistencia sanitaria.

Una interpretación de este tipo corre el riesgo de derivar en condenas automáticas del asegurador cada vez que uno de los facultativos, profesionales o centros integrados en su cuadro médico incurra en errores o negligencias puntuales que provoquen daños resarcibles a los pacientes asegurados, lo cual aboca a una responsabilidad solidaria de carácter cuasi-objetivo (aplicando la doctrina de la solidaridad impropia o por interés social, para tutela de los derechos de los perjudicados $)^{53}$, eludiendo cualesquiera valoraciones sobre la mayor o menor diligencia desplegada por el asegurador en la organización y gestión de la infraestructura sanitaria que pone a disposición de sus asegurados: la suficiencia, diversidad y calidad de los servicios sanitarios organizados por el asegurador y las circunstancias de cada caso concreto ${ }^{54}$.

\footnotetext{
51 Art. 46 Ley 44/2003, de 21 de noviembre, de Ordenación de las Profesiones Sanitarias: "Los profesionales sanitarios que ejerzan en el ámbito de la asistencia sanitaria privada, así como las personas jurídicas o entidades de titularidad privada que presten cualquier clase de servicios sanitarios, vienen obligados a suscribir el oportuno seguro de responsabilidad, un aval u otra garantía financiera que cubra las indemnizaciones que se puedan derivar de un eventual daño a las personas causado con ocasión de la prestación de tal asistencia o servicios".

Las comunidades autónomas, en el ámbito de sus respectivas competencias, determinarán las condiciones esenciales del aseguramiento, con la participación de los profesionales y del resto de los agentes del sector.

En el supuesto de profesiones colegiadas, los colegios profesionales podrán adoptar las medidas necesarias para facilitar a sus colegiados el cumplimiento de esta obligación".

52 Vid. el estudio de $\mathrm{M}^{\mathrm{a}}$ del Carmen Gónzalez Carrasco. "Algunas cuestiones acerca de los seguros privados de salud en España”, Aranzadi Civil-Mercantil, núm. 20/2007.

53 Vid. por todas, la relevante Sentencia del Tribunal Supremo, Sala Primera, de lo Civil, de 7 de noviembre de 2000, según la cual: "La doctrina jurisprudencial viene reconociendo la aplicabilidad de la solidaridad impropia (en cuanto no resulta de pacto o de disposición legal) en los casos que el resultado dañoso es una consecuencia de varias aportaciones causales sin que sea posible determinar, mediante un módulo aritmético (cantidad fija o tanto por ciento, de un modo preciso o por aproximación), la entidad de las respectivas participaciones -principio de la indiscernibilidad-. Esta solución no exige que se dé una actuación conjunta, ni que la causa sea común o única, siendo aplicable a casos como el de autos en que se aprecian causas concurrentes, autónomas, susceptibles de producir cada una de ellas por sí sola el resultado dañoso objeto de la litis".

${ }^{54}$ Como señala la mejor doctrina, "el juicio sobre la causalidad, que debería ser objetivo y cuya existencia es una cuestión fáctica sustraída del ámbito de decisión del juzgador, se ha convertido en una herramienta al servicio del operador jurídico para discriminar las acciones que generan responsabilidad de las que deben quedar impunes". Carlos Gómez Ligüerre. Solidaridad y Derecho de Daños. Los Limites de la Responsabilidad Colectiva, Thomson Civitas, Madrid, 2007, pp. 308-309. Es necesario, a tales fines, distinguir con claridad entre la causalidad y la imputación objetiva del resultado dañoso. Vid. Fernando PAntaleón Prieto. "Causalidad e imputación objetiva: criterios de imputación”, en AA.VV., Centenario del Código Civil, T. II, Fundación Ramón Areces, Madrid, 1990, p. 1561: "El problema de la existencia o no de relación de causalidad entre la conducta del posible responsable y el resultado dañoso no debe ser confundido con el problema, radicalmente distinto, de si el resultado dañoso causalmente ligado a la conducta en cuestión puede o no ser puesto a cargo de aquella conducta como obra de su autor, de
} 
Asimismo, una interpretación motivada en exceso por el espíritu de protección de los consumidores y usuarios impide o elude examinar a fondo un elemento fundamental en la compleja estructura del seguro de asistencia sanitaria: la libertad de elección de facultativos, profesionales y centros sanitarios por el asegurado dentro del cuadro médico-asistencial organizado y puesto a su disposición por el asegurador, que constituye una piedra angular en la estructura del seguro de asistencia sanitaria ${ }^{55}$ y se puede y debe erigir en un factor clave para resolver cuestiones de responsabilidad por incumplimiento o cumplimiento defectuoso (en forma de daños causados por una mala praxis profesional o un mal funcionamiento de servicios sanitarios de diagnóstico, quirófano o tratamiento) de la asistencia sanitaria.

Afirmar, como hace el Alto Tribunal, que el hecho de fijar un cuadro médico y asistencial determinado supone ya limitar las posibilidades de elección del asegurado y obligarle a ser asistido por un profesional o centro determinado (el que él elija), terminaría con la esencia del contrato de asistencia sanitaria, equiparándolo prácticamente a un contrato de seguro de enfermedad lato sensu en el que el asegurado puede elegir libremente los centros y profesionales siendo luego reembolsado del pago satisfecho. Obviamente un asegurador de asistencia sanitaria no puede incluir en sus servicios a todos los profesionales que libremente decida elegir el asegurado. Es necesario encontrar una solución intermedia al problema si no se quiere abocar el sistema español de asistencia sanitaria a un encarecimiento progresivo de las primas e incluso a un sistema similar al "managed health care" estadounidense.

En la libertad de elección del prestador del servicio sanitario por el asegurado reside probablemente la diferencia fundamental entre el seguro de asistencia sanitaria (y el seguro de dependencia) y otros seguros asistenciales o cualesquiera seguros que incluyen coberturas accesorias de prestación de servicios ${ }^{56}$. En el seguro de asistencia

acuerdo con los criterios establecidos al efecto por el legislador o deducidos por el operador jurídico de la estructura y función de las normas de responsabilidad correspondientes". Así, cuando los agentes supuestamente causantes del daño son varios, la distribución de responsabilidad debe llevarse a cabo en sede de imputación objetiva, evitando juicios de imputación automática e indiscriminada y haciendo sólo responsables a los agentes cuyo comportamiento tenga una incidencia real y efectiva en la producción del daño reclamado, con fundamento en la doctrina de los cursos causales eficaces. La solidaridad en derecho de daños sólo debería ser la solución a aquellas situaciones en que surjan problemas de identificación (y yo diría también de exigencia efectiva) de la responsabilidad individual, siempre -entiendo- que el sujeto a quien se reclama responsabilidad contribuya de forma real y efectiva (causa adecuada o causa eficaz debidamente acreditada en el caso concreto) con su comportamiento a la producción del daño reclamado.

55 De hecho, la composición verdaderamente plural y equilibrada del cuadro médico y asistencial se tendrá muy en cuenta para optar por la contratación de uno u otro seguro de asistencia sanitaria. Aunque en otras ocasiones, los pacientes optan por un seguro si éste incluye a un concreto facultativo o centro hospitalario que le ofrece mayor confianza. Cfr., Joaquín Ataz López. Los médicos y la responsabilidad civil, Montecorvo, Madrid, 1985, p. 227.

56 En éstos (seguros de asistencia turística, seguros de decesos, seguros de defensa jurídica...seguros multirriesgo hogar, seguros multirriesgo automóvil), el profesional que presta el servicio o realiza una obra suele imponerse por el asegurador, o bien se deja un reducidísimo margen de elección al asegurado, motivo por el que el asegurador debería garantizar en todo caso del buen fin, el resultado buscado por el asegurado, la adecuada prestación del servicio u realización de la obra (v.gr., reparación del objeto siniestrado) efectuado por el profesional, $y$, en consecuencia, debe responder de los daños ocasionados por una ejecución defectuosa del servicio u obra, independientemente de si ha sido ejecutada por profesionales 
sanitaria el asegurado debe gozar normalmente de un margen razonablemente amplio de libertad de elección entre un cuadro asistencial plural y equilibrado en condiciones objetivas de cualificación profesional y técnica, por lo que, siempre que el asegurador proporcione una libertad de elección razonable a profesionales y centros sanitarios que presenten condiciones similares de formación, experiencia y medios técnicos y humanos, habría cumplido con su obligación de proporcionar cobertura asistencial, aunque -dado que asume una obligación de resultado-deberá garantizar la efectiva prestación de esos servicios, es decir, el acceso a los mismos cuando sea solicitado por el asegurado. Pero su obligación, en principio, debería llegar hasta ahí. El asegurador no puede garantizar la correcta ejecución o prestación material de los servicios sanitarios, ya que no influye directa o indirectamente en los criterios médicos, desligándose así de la responsabilidad por daños y perjuicios derivados de una mala práctica profesional por parte de los profesionales y centros que prestan el servicio sanitario al asegurado ${ }^{57}$.

Es inherente a la obligación de resultado del asegurador de asistencia sanitaria, que se compromete a prestar cobertura asistencial en forma de servicios sanitarios si se produce una situación de necesidad con motivo de la alteración del estado de salud, la provisión de medios humanos y materiales en condiciones objetivas de idoneidad, número, pluralidad y calidad para garantizar al asegurado una libertad de elección real o razonable entre los facultativos, profesionales y centros clínicos y hospitalarios de su cuadro médico. De esta forma, el asegurador ofrecería una garantía en abstracto -en el sentido de razonablemente previsible- de la correcta prestación material de esos servicios: si los profesionales y centros sanitarios incluidos en su cuadro son idóneos para atender de manera suficiente y razonable todas las posibles dolencias del asegurado que no estén excluidas de cobertura, y con una calidad contrastada tanto en titulación, formación, y experiencia, como en medios materiales y técnicos, el resultado esperable es que esos profesionales y centros sanitarios ofrezcan al asegurado la asistencia idónea para recuperar su estado de salud ante cualquier contingencia en forma de enfermedad, lesión o accidente. Pero lo que no puede

incluidos en su infraestructura empresarial o por terceros independientes subcontratados de forma específica por el asegurador para prestar servicios a sus asegurados. La imputación de responsabilidad se justificaría en la responsabilidad contractual por hechos cometidos por los auxiliares, ya que en este caso los prestadores de servicios actúan siguiendo las instrucciones del asegurador. Vid. en la doctrina italiana, VolPe Putzolu. "Prestazione di servizi nell'evoluzione del rapporto assicurativo", cit., p. 16, remitiéndose al art. 1228 del Codice Civile Italiano, que regula la responsabilidad contractual por actos de los auxiliares: "Salva diversa volontà delle parti, il debitore che nell'adempimento dell'obbligazione si vale dell'opera di terzi, risponde anche dei fatti dolosi o colposi di costoro".

57 El debate sobre el equilibrio profesional de los facultativos incluidos en el cuadro médico, en relación con factores como la formación, la experiencia, el prestigio y los medios técnicos disponibles, quedará normalmente en el plano de las apreciaciones subjetivas, sin perjuicio de que en situaciones puntuales pueda acreditarse un desequilibrio evidente que se traduciría en la falta de una libertad de elección real, ya por el escaso número de profesionales en una disciplina o ya por la notoria diferencia de cualificación y prestigio profesional entre los distintos facultativos integrados en el cuadro del asegurador. Estas circunstancias o situaciones puntuales, debidamente acreditadas, pueden servir para justificar la responsabilidad del asegurador de asistencia sanitaria por los daños derivados de una falta de asistencia por profesionales adecuados o idóneos para el diagnóstico y tratamiento acertado de una enfermedad o dolencia, o por los daños derivados de una mala praxis profesional de los facultativos y centros concertados por el asegurador. 
garantizar el asegurador es la correcta ejecución de esos servicios sanitarios, porque no interviene en la prestación material de los mismos, ni se inmiscuye ni predetermina los criterios y decisiones médicas, salvo que se pruebe lo contrario en cada caso concreto (por ejemplo señalando un concreto profesional o centro médico para realizar un tratamiento particular o específico al paciente).

En suma, el asegurador de asistencia sanitaria no es un mero intermediario, sino que debe garantizar una asistencia amplia y de calidad, facilitando una libertad de elección real de centros y profesionales. Pero esa garantía de servicios amplios y de calidad a disposición de los asegurados, que efectivamente forma parte de la publicidad de estas compañías, no puede derivar en una garantía de la correcta ejecución del servicio asistencial, pues por mucho que los facultativos y centros asistenciales tengan la condición de auxiliares contractuales o de cumplimiento del servicio comprometido por el asegurador (vinculado con ellos mediante contratos a favor de terceros), actúan siempre con organización y criterios profesionales propios, sin que se pueda inmiscuir el asegurador en dichos criterios de ejercicio de la "lex artis ad hoc". Así pues, la garantía del asegurador no se puede ni se debe extender a la correcta ejecución de los servicios por esos terceros auxiliares, salvo en casos muy puntuales en los que sea el propio asegurador quien imponga o recomiende un concreto centro o facultativo. En definitiva, la defectuosa prestación médica no constituye un incumplimiento de la obligación comprometida por el asegurador con los asegurados.

Entiendo, en fin, que una adecuada respuesta al problema del alcance de la obligación del asegurador de asistencia sanitaria debe tener en cuenta la mayor o menor diligencia desplegada por el asegurador en la organización de una infraestructura sanitaria idónea y de calidad para atender las diversas dolencias o enfermedades incluidas en la cobertura asistencial de la póliza, y, en relación con ello, la existencia en cada caso concreto de una libertad de elección razonable (que, aunque no libertad plena, sea real y no ficticia dentro de la limitación que supone el cuadro médico-asistencial) de profesionales y centros sanitarios por los asegurados. Estos elementos se sitúan a su vez en relación directa con la compleja estructura contractual que subyace a la dinámica u operativa de este seguro. La respuesta que finalmente se ofrezca, tiene que sustentarse en el complejo entramado negocial que está tras la operativa habitual de estos seguros; en la concatenación causal entre los distintos contratos que subyacen a la relación triangular asegurador-médicoasegurado o asegurador-centrosanitario-asegurado.

Por lo tanto, el asegurador debería responder únicamente de los daños causados por la falta de asistencia o asistencia tardía por parte de esos auxiliares. También, si no ha creado una infraestructura lo suficientemente amplia, equilibrada y de calidad contrastada para garantizar en abstracto la efectiva y correcta prestación de los servicios sanitarios comprometidos en la póliza: no ofrece profesionales para disciplinas concretas; designa un concreto profesional o centro para un acto médico; ofrece un número reducido o claramente inadecuado para satisfacer la demanda; no ofrece prueba de diagnóstico ni tratamientos específicos incluidos en la póliza; incluye profesionales y centros sin la cualificación necesaria, que claramente imperitos o que no disponen de la idoneidad adecuada, o que han incurrido reiteradamente en 
negligencias profesionales. Y en todos estos casos, aquí sí, incluyendo los intereses sancionadores del artículo 20 LCS.

\section{CONSIDERACIONES FINALES}

La posición de la Jurisprudencia, aunque parte del carácter objetivo de la responsabilidad contractual propia del deudor por los actos de sus auxiliares (responsabilidad indirecta) basada en el principio "cuius est commodum eius est periculum", contiene aún el germen de una responsabilidad basada en la culpa in eligendo y culpa in vigilando del asegurador. Es decir, que un acto negligente del médico u hospital deriva en una responsabilidad por negligente selección y vigilancia de ese medico u hospital, frustrando las expectativas de los asegurados e incumpliendo así la obligación de garantía en la correcta ejecución que se desprende del contrato de seguro. Sin embargo, como ha demostrado la doctrina científica más autorizada, en la responsabilidad contractual por actos de los auxiliares (que, por cierto, a estos fines resulta irrelevante si son o no dependientes), la responsabilidad del deudor es objetiva: responde del incumplimiento o cumplimiento defectuoso de la prestación comprometida, al margen de si existió culpa o no en los auxiliares que intervienen en la ejecución de esa prestación por voluntad del deudor ${ }^{58}$.

Considerar, como hace el Tribunal Supremo, que el asegurador garantiza la correcta ejecución de los servicios sanitarios, constituye una posición maximalista orientada exclusivamente a la mayor seguridad del asegurado en su condición de consumidor de servicios sanitarios, omitiendo cualquier otra consideración analítico-objetiva sobre la estructura de la causa del contrato (causa-función) de seguro de asistencia sanitaria, sobre el juego de intereses que subyace al mismo y, también, sobre funcionamiento eficiente del sistema, del mercado de seguros de asistencia sanitaria, que tanta importancia tiene en España. El asegurador garantiza la efectiva prestación del servicio cuando éste sea requerido por el asegurado, al tiempo que asegura también la implementación de un cuadro asistencial razonablemente amplio y de calidad para atender las dolencias de los asegurados. Pero no puede extenderse su obligación genérica hasta garantizar la correcta ejecución de la prestación sanitaria, en la que no participa, salvo que se pruebe otra cosa, o salvo en casos concretos donde el asegurador nombra un centro o profesional específico al que imparte instrucciones para las pruebas, tratamientos e intervenciones del asegurado. Casos excepcionales en los que sí podría recurrirse a la doctrina de la causalidad adecuada o eficiente en la producción del daño final.

Es decir, la responsabilidad civil por cumplimientos defectuosos del servicio sanitario, por errores o negligencias médicas al desplegar un servicio sanitario concreto a un asegurado, no se trasvasa al asegurador por cuya cuenta e interés se presta ese servicio, porque, "a efectos de afirmar la responsabilidad contractual indirecta del deudor y principal frente a su acreedor, lo único decisivo es si la conducta de su auxiliar,

\footnotetext{
58 Manuel JoRdano Fraga. La responsabilidad del deudor por los auxiliares que utiliza en el cumplimiento, Civitas, Madrid, 1994, p. 522.
} 
que jurídicamente se le imputa, constituye o no un incumplimiento de su obligación, sin que, naturalmente, descargue al deudor/principal de su responsabilidad por su auxiliar, el hecho de que éste, a su vez, haya incumplido la obligación en que resulta deudor del principal ${ }^{\prime 59}$. Entonces, el principal/asegurador respondería por los actos del profesional/auxiliar, sólo si la conducta antijurídica de éste constituye un incumplimiento de la obligación que el asegurador tiene con el asegurado. Expresado de otra forma: en el esquema del seguro de asistencia sanitaria, el asegurador responde si la conducta de los profesionales y centros sanitarios que jurídicamente se le imputa por la conexión contractual (causal) existente entre el contrato de servicios a favor de terceros y el contrato de seguro de asistencia sanitaria, constituye o no un incumplimiento de su obligación como tal asegurador respecto a los asegurados. Ergo, si se considera, como aquí proponemos, que el asegurador no se obliga a garantizar la correcta ejecución del servicio sanitario, sino solamente la efectiva prestación de ese servicio al tiempo de ser solicitado, el cumplimiento defectuoso del servicio sanitario por el médico o centro sanitario auxiliar de aquél en virtud del contrato de prestación de servicios a terceros, no constituye un cumplimiento defectuoso de la obligación del asegurador, cuyo alcance es más limitado.

Así pues, la responsabilidad civil por errores o negligencias médicas deberá imputarse al centro o profesional responsable, pero no al asegurador de asistencia sanitaria. Salvo que el asegurador no hubiera organizado un cuadro asistencial razonablemente amplio, plural, equilibrado y de calidad para garantizar un acceso y disfrute pacífico de los servicios sanitarios comprometidos, permitiendo una libertad de elección lógica o sensata (tampoco una plena libertad de elección, que no se ajusta al esquema de este seguro) al asegurado. Entonces, sólo podría imputarse responsabilidad al asegurador en circunstancias puntuales, donde un error o negligencia sanitaria pudiera atribuirse a una incorrecta organización y gestión (selección y vigilancia) de los profesionales y centros sanitarios incluidos en su cuadro asistencial; por ejemplo, como consecuencia de la nula o escasa libertad de elección (un solo profesional, centro de diagnóstico o especialista); o a raíz de la inclusión y mantenimiento en el cuadro asistencial de profesionales o centros que no reúnen las características profesionales adecuadas o que han incurrido en negligencias reiteradas; o en casos de impericias manifiestas en la elección de tratamientos, práctica de pruebas de diagnósticos o intervenciones quirúrgicas.

La doctrina del Tribunal Supremo se presenta como una posición maximalista, ultragarantista para los asegurados. Y con ello convierte al seguro de asistencia sanitaria en factor de atribución o imputación (cuasi-objetiva) de responsabilidad, diluyendo la figura del verdadero responsable, y convirtiéndolo e instrumento de socialización de daños ${ }^{60}$ (Veiga Copo. Tratado, T. II, $6^{\mathrm{a}}$ ed., 2019, p. 1905).

Entiendo que esa interpretación no se ajusta, además, a la estructura íntima del tipo de seguro y además puede ser fuente de posibles ineficiencias en el sistema privado de salud.

\footnotetext{
59 Jordano Fraga. La responsabilidad del deudor por los auxiliares que utiliza en el cumplimiento, cit., p. 529.

60 Veiga Copo. Tratado del Contrato de Seguro, T. II, 6 ed., 2019, p. 1905.
} 
En términos de eficiencia económica (análisis económico del derecho), la doctrina del Tribunal Supremo haciendo responsable cuasi-automático al asegurador de asistencia sanitaria por las negligencias de su cuadro médico-asistencial puede producir eficiencias desde la perspectiva de la seguridad (bienestar) de los consumidores, máxime cuando están en juego bienes fundamentales como la vida y la salud. Pero puede ser una perspectiva equívoca, porque el excesivo garantismo puede provocar efectos indeseados en el conjunto del mercado de seguros de asistencia sanitaria para acabar repercutiendo negativamente en los mismos intereses de aquellos a quienes se pretende proteger. Los aseguradores no disponen de provisiones técnicas para afrontar las indemnizaciones que se les imputan como consecuencia de errores médicos y clínicos; errores en los que no tienen intervención alguna salvo en casos excepcionales. De modo que esas indemnizaciones generan pérdidas en todo caso. El riesgo que cubren estos seguros es el de la necesidad de asistencia sanitaria propiamente dicha; no el de las consecuencias de una incorrecta asistencia sanitaria. Por lo tanto, las pérdidas pueden provocar un incremento progresivo de las primas y una progresiva pérdida de calidad en los cuadros asistenciales, reduciendo el número de facultativos y centros, prestando más atención a criterios puramente económicos que de asistencia y cuidado de la salud. Además puede provocar una falta de adecuación al riesgo de las pólizas de responsabilidad civil.

¿Para qué ofertar amplias coberturas de máxima calidad si el asegurador va a responder en cualquier circunstancia? Es decir, la doctrina ultragarantista de nuestros tribunales puede repercutir a medio plano negativamente en la eficiencia del sistema de asistencia sanitaria, tan extendido en nuestro país, provocando un gradual incremento del precio de las primas al tiempo que una reducción paulatina del cuadro asistencial; más aún si se piensa que la búsqueda del beneficio y el incremento del riesgo asumido, forzará condiciones económicas más restrictivas para los profesionales y centros, muchos de los cuales se negarán a prestar sus servicios para las compañías aseguradoras en condiciones económicas poco favorables para ellos (en comparación con el precio de mercado o precio habitual de una consulta o atención médica en régimen estrictamente privado, es decir, en contratación directa con el paciente).

Además, se produce un solapamiento entre aseguradores de asistencia sanitaria y aseguradores de responsabilidad civil. Siendo obligatorio el seguro de responsabilidad civil de profesionales y centros sanitarios ${ }^{61}$, será habitual que los aseguradores de asistencia sanitaria que abonan indemnizaciones se dirijan luego contra los aseguradores de responsabilidad civil de sus profesionales y centros; de hecho, suelen exigir a los centros y profesionales concertados sumas aseguradas elevadas en previsión de esa circunstancia; lo cual redunda igualmente en un incremento progresivo de las primas de responsabilidad civil. Y si las sumas aseguradas de responsabilidad civil no son suficientes para cubrir las indemnizaciones abonadas por las compañías de asistencia sanitaria por incorrectas prestaciones de los servicios sanitarios de su cuadro médico concertado, es muy posible también que estas compañías se dirijan directamente

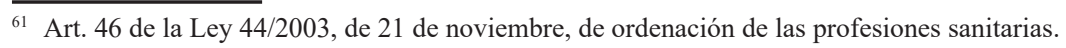


contra los centros o profesionales para reclamar la cantidad no cubierta por la póliza de responsabilidad civil $^{62}$.

Pero tampoco es eficiente un escenario inverso: un escenario sin responsabilidad alguna de los aseguradores de asistencia sanitaria; lo cual, conduciría al mismo resultado que un escenario de responsabilidad plena y automática. En este caso, los aseguradores no prestarían la atención debida para crear un cuadro asistencial amplio y de calidad para procurar una libertad de elección razonable al asegurado entre facultativos y centros de condiciones similares de conocimientos, experiencia, medios técnicos, etc.

En definitiva, a la vista de todos los argumentos jurídicos y económicos expuestos, considero adecuada una posición ecléctica que excluya en principio a los aseguradores de asistencia sanitaria de la responsabilidad por errores y negligencias de los profesionales de su cuadro asistencial, pero que les haga responsables de los daños y perjuicios derivados de una infraestructura pobre o inadecuada y de los errores y negligencias médicas directa o indirectamente asociados a la falta de medios humanos y materiales suficientes y de calidad o a la falta de control y vigilancia a la hora de seleccionar y mantener en el cuadro a profesionales y centros manifiestamente imperitos o que hubieran incurrido en negligencias reiteradas, especialmente cuando la entidad imponga o recomiende un centro o profesional específico para tratar la dolencia de un asegurado.

No ignoro que el problema de esta solución reside en la prueba objetiva de estas situaciones especiales; y que la consideración de la suficiencia o insuficiencia del cuadro médico asistencial dependerá mucho de la sensibilidad de cada juzgador o tribunal, dando como resultado resoluciones dispares que vayan en detrimento de la seguridad jurídica. Pero tampoco es óptima la solución contraria de considerar responsable al asegurador prácticamente en todas las situaciones en que se produce una asistencia sanitaria defectuosa, como viene ocurriendo hasta el momento. Y sobre todo entiendo que es contraria a las reglas de la imputación objetiva de la responsabilidad, ampliando extraordinariamente los cursos causales concurrentes en el daño final; máxime cuando habitualmente es claro quién o quiénes resultan ser los responsables directos del daño, y cuándo estos obligatoriamente disponen de un seguro de responsabilidad civil que, cuando menos, ha de servir para paliar el riesgo de insolvencia del responsable directo que justifica las más de las veces la imputación de responsabilidad al asegurador de asistencia sanitaria por aplicación de las reglas de la solidaridad impropia en los mecanismos de responsabilidad civil extracontractual y contractual.

De modo que, ¿no es más lógico que la responsabilidad por errores y negligencias se solvente mediante el mecanismo del seguro de responsabilidad civil exclusivamente?

\footnotetext{
62 Vid. al respecto la STS de 31 de marzo de 2004, que trata sobre una acción de reclamación instada por una compañía de asistencia sanitaria contra un médico contratado por la misma para prestar asistencia sanitaria a sus asegurados y contra su esposa (régimen de gananciales), para recuperar las cantidades abonadas a unos asegurados en concepto de indemnización por los daños causados por el médico demandado en el ejercicio de su profesión. La sentencia determina que las obligaciones extracontractuales del profesional serán de la responsabilidad y cargo de la sociedad de gananciales, ex art. 1366 CC. Vid. el comentario de Nieves Moralejo Imbernón, en Cuadernos Civitas de Jurisprudencia Civil, nº 67, 2005, pp. 115 y ss.
} 
Sin descartar, incluso, la intervención administrativa para exigir una cobertura mínima de estos seguros para el ejercicio de actividades sanitarias privadas, discriminando en función de la especialidad. A salvo, claro está de los casos que antes se han apuntado en que el asegurador de asistencia sanitaria no ofrezca una cobertura suficiente cualitativa y cuantitativamente, o falle en los controles mínimos profesionales y técnicos de los centros y profesionales que integran su cuadro asistencial.

En cualquier caso, el conjunto del sistema necesita urgentemente una reforma legal que aporte seguridad jurídica. Una reforma que aporte un concepto claro del seguro de asistencia sanitaria, de la naturaleza, contenido y alcance de la prestación del asegurador y de un régimen jurídico acorde con ello. Y acompañado de un régimen reglamentario que discipline los aspectos organizativos y funcionales básicos del sistema, tanto en lo relativo a la implementación del mismo, como a las relaciones entre el asegurador y los profesionales y centros sanitarios, y también a las relaciones entre el asegurador y los profesionales sanitarios con los asegurados, siempre prestando especial atención a la salud como interés de referencia de todo el sistema.

Reforma normativa que ha sido ya diseñada en al menos dos importantes proyectos finalmente frustrados.

En el Anteproyecto de Ley de Contrato de Seguro del año 2010, el Capítulo IV (Seguro de enfermedad), artículo 102 establecía que: 1. Por el seguro de enfermedad el asegurador se obliga, dentro de los límites establecidos en la Ley y en el contrato, a reparar las consecuencias económicas producidas por la enfermedad del asegurado. 2. La prestación del asegurador podrá consistir en el reembolso al asegurado de los gastos derivados de la asistencia sanitaria o en el abono de una indemnización a tanto alzado en el caso de que se produzca la invalidez, temporal o permanente, del asegurado como consecuencia de la enfermedad. La prestación podrá consistir también en garantizar al asegurado los servicios de asistencia sanitaria, debiendo el asegurador poner a disposición del asegurado dichos servicios y asumir directamente su coste.

En el artículo 583-28 del Anteproyecto de Código Mercantil de 2013 se proponía igualmente que: 1. Por el seguro de enfermedad el asegurador se obliga, dentro de los límites establecidos en este título y en contrato, a reparar las consecuencias económicas producidas por la enfermedad del asegurado. 2. La prestación del asegurador podrá consistir en el reembolso al asegurado de los gastos derivados de la asistencia sanitaria o en el abono de una indemnización a tanto alzado en el caso de que se produzca la invalidez, temporal o permanente, del asegurado como consecuencia de la enfermedad, o en caso de hospitalización u otras contingencias pactadas en el póliza relativas a la salud del asegurado. La prestación podrá consistir también en garantizar al asegurado la recepción de asistencia sanitaria, debiendo el asegurador poner a disposición del asegurado dichos servicios y asumir directamente su coste. El asegurador también podrá obligarse a pagar directamente sus servicios a los prestadores sanitarios cuya atención se ofrezca en la póliza. 3. Cuando el seguro de enfermedad garantice la recepción de asistencia sanitaria, no podrán aplicarse exclusiones temporales o plazos de carencia para aquellas actuaciones sanitarias comprendidas en el objeto y límites del contrato que, por su urgencia y gravedad, el asegurado precise con carácter inmediato. 
Esto es, en ambos proyectos el prelegislador propuso una definición más clara del alcance de la prestación asumida por el asegurador de asistencia sanitaria, consistente en garantizar al asegurado la recepción o el acceso a los servicios de asistencia sanitaria, poniendo a su disposición dichos servicios asumiendo directamente su coste. Por lo tanto no parece que se esté asumiendo la posición del TS en el sentido de que el asegurador garantice el buen fin de la asistencia prestada por los facultativos y centros incluidos en el cuadro médico de la compañía, sino más bien una posición más ajustada al compromiso verdaderamente asumido y que puede asumir: poner a disposición los medios necesarios para que los asegurados reciban la asistencia sanitaria comprometida por el asegurador, pero sin ir más allá garantizando la correcta ejecución del servicio al no tener influencia alguno en los criterios médicos-sanitarios de los profesionales.

Así parece haberse concretado en el seguro de dependencia regulado en el artículo 106ter apartado 3, letra c) LCS, introducido por la Disposición final 1.4 de la Ley 20/2015, de 14 de julio, donde se explicita que la prestación del asegurador de asistencia sanitaria podrá consistir "en garantizar al asegurado la prestación de los servicios de asistencia, debiendo el asegurador poner a disposición del asegurado dichos servicios y asumir directamente su coste". No parece, pues, que la prestación vaya más allá de la mera puesta a disposición de los servicios asistenciales (de dependencia) en condiciones suficientes para que el asegurado pueda elegir el centro de prestación del servicio; no, por tanto, la garantía de correcta ejecución del servicio asistencial de dependencia.

Creo en todo caso, a la espera de una futurible reforma normativa que resuelva definitivamente el problema, que el seguro o la prestación de asistencia sanitaria debe conservar siempre su condición de seguro asistencial, de modo que el asegurador no cumple con su prestación limitándose a abonar los servicios prestados por los centros y profesionales concertados a tal fin. Se conciba como un "tertium genus" asistencial ${ }^{63}$ o como una prestación en especie de seguros de daños en el patrimonio (en forma de prestación de un servicio reparador), la prestación del asegurador debe interpretarse en todo caso como una obligación de organización y cobertura suficiente, cualitativa y cuantitativamente, de la prestación sanitaria a sus asegurados; una garantía de la prestación del servicio que, a mi juicio, no debería extenderse al resultado final, respondiendo en caso de prestaciones defectuosas por parte de profesionales y centros que actúan con libertad de criterio (como auxiliares plenamente independientes, si se quiere), salvo que concurriesen las excepcionales circunstancias antes indicadas, que más tienen que ver con un incumplimiento de la obligación fundamental de garantía de prestación del servicio en condiciones razonables que con la garantía de la correcta ejecución de prestaciones asistenciales en las que el asegurador -por lo general- no interviene ni directa ni indirectamente.

\footnotetext{
${ }^{63}$ Como aquí se defiende, siendo el riesgo asegurado la situación de necesidad que provoca la enfermedad, emergiendo así el aspecto fundamental de la ayuda en situaciones de necesidad en forma organización del servicio de asistencia sanitaria, sobre el aspecto secundario del daño en el patrimonio.
} 


\section{BIBLIOGRAFÍA}

AtAz López, J. Los médicos y la responsabilidad civil, Montecorvo, Madrid, 1985.

CARBAJO CASCÓN, F. La responsabilidad civil del asegurador de asistencia sanitaria, Fundación Mapfre, Instituto de Ciencias del Seguro, Cuadernos de la Colección, Madrid, 2012.

De ÁNGEL YAGÜEZ, R. “¿Responde el asegurador de asistencia sanitaria por la culpa de los médicos incluidos en sus listas?", en Moreno Martínez, J.A. (Coord.), La Responsabilidad Civil y su problemática actual, Dykinson, Madrid, 2008, pp. 140 y ss.

De Angulo Rodríguez, L. "Sobre la regulación de los seguros de personas", en AA.VV., Estudios de Derecho Mercantil en Homenaje al Profesor Justino F. Duque Dominguez, Vol. II, Universidad de Valladolid/Caja Duero, Valladolid, 1998, pp. 1157-1158.

Donati, A. Tratatto del diritto delle assicurazioni private, Milano, 1954.

FANelli, G. "La "summa divisio" delle assicurazioni private: riflessioni su di un vecchio problema", en AA.VV. Saggi di Diritto delle Assicurazioni, Giuffrè, Milano, 1971, pp. 493 y ss.

Garrigues, J. Contrato de Seguro Terrestre, $1^{\text {a }}$ ed., Madrid, 1973. $2^{\mathrm{a}}$ ed., Madrid, 1983

Gómez Ligüerre, C. Solidaridad y Derecho de Daños. Los Límites de la Responsabilidad Colectiva, Thomson Civitas, Madrid, 2007.

GonzÁlez Bueno, G. "Hacia nuevas formas de vender seguridad a través de prestaciones de asistencia", Revista Española del Seguro (RES), n 39, 1984, pp. 442 y ss.

GónZalez CARrasco, $\mathrm{M}^{\mathrm{a}} \mathrm{C}$. "Algunas cuestiones acerca de los seguros privados de salud en España”, Aranzadi Civil-Mercantil, núm. 20/2007.

Idem, "Asistencia sanitaria, un ramo con fuerza propia", Actualidad Aseguradora, marzo 1994, pp. 25 y ss.

Jordano Fraga, M. La responsabilidad del deudor por los auxiliares que utiliza en el cumplimiento, Civitas, Madrid, 1994.

Marco ArCalÁ, L.A. Seguros de personas. Aspectos generales, Thomson-Aranzadi, Navarra, 2006.

Martín CaSALS, M. "Líneas generales sobre la responsabilidad de las entidades de seguros de salud en las reclamaciones por efectos adversos, errores o negligencias médicas", RES 2006, $n^{\circ} 128$, pp. 803 y ss.

Martín Casals, M./Ribot Igualada, J./Solé Feliú, J. La responsabilidad de las entidades de seguros de salud en las reclamaciones judiciales por errores o negligencias médicas, Cuadernos de SEAIDA, noviembre de 2006.

Martínez-Gijón Machuca, P. El seguro privado de asistencia sanitaria, Fundación Mapfre, Madrid, 2002.

Nyman, J.A. The Theory of Demand for Health Insurance, Stanford University Press, California, 2003.

Pantaleón Prieto, F. "Causalidad e imputación objetiva: criterios de imputación”, en AA.VV., Centenario del Código Civil, T. II, Fundación Ramón Areces, Madrid, 1990, pp. 1561 y ss. 
Sánchez Calero, F. “Comentario al artículo 1”, en Sánchez Calero, F. (Dir), Comentarios a la Ley de Contrato de Seguro, Thomson-Aranzadi, $4^{\mathrm{a}}$ ed., 2010, pp. 36-37.

Sánchez Calero, F. “Comentario al artículo 105 LCS”, en Sánchez Calero, F. (Dir), Comentarios a la Ley de Contrato de Seguro, Thomson-Aranzadi, $4^{\mathrm{a}}$ ed., 2010, pp. 2694 y ss.

SCALFI, G. I contratti di assicurazione. Asicurazione dei danni, Torino 1991.

SCALFI, G. "Dalla classificazione dualistica alla concezione pluralistica dei contratti di assicurazione: contratto o contratti di assicurazione?”, Assicurazione, 1995-3, pp. 143 y ss.

SCALFI, G. L'assicurazione tra rischio e finanza, Giuffrè, Milano, 1992.

Tirado SuÁrez, F.J. “¿El seguro de asistencia sanitaria y el seguro de enfermedad son el mismo ramo o son ramos diferentes?", Actualidad Aseguradora, septiembre 1992, pp. 28 y ss.

URÍA, R. "Orientaciones modernas sobre el contrato de seguro", Revista de Derecho Mercantil (RDM), no 84, 1962, pp. 263 y ss.

VÁQuez De Padura, M. "La responsabilidad ante el paciente de las entidades de seguro de asistencia sanitaria", RES 2006, n 128, pp. 847-848.

Veiga Copo, A.B. Tratado del Contrato de Seguro, T. I, 6 ${ }^{\text {a }}$ ed., Thomson Reuters Civitas, Madrid, 2019.

Vergez, M. "Los seguros de accidentes y de enfermedad y asistencia sanitaria en la Ley de Contrato de Seguro (arts. 100 a 106)", en Evelio VERDERA i TUELLS (Coord.), Comentarios a la Ley de Contrato de Seguro, Vol. I, Madrid, 1982, pp. 1069 y ss.

Volpe Putzolu, G. "Prestazione di servizi nell'evoluzione del rapporto assicurativo", en Assicurazioni, 2000-I, pp. 7 y ss. 
